\title{
Flora y micobiota en riesgo y endémicas en el municipio San Sebastián del Oeste, Jalisco, México
}

\section{Threatened and endemic flora and mycobiota in the municipality San Sebastián del Oeste, Jalisco, Mexico}

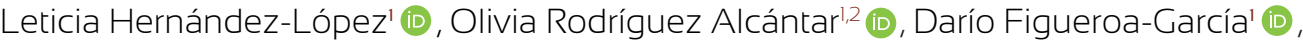 \\ Jesús Jacqueline Reynoso Dueñas' (D), Armando Arias' (10)
}

\section{Resumen:}

Antecedentes y Objetivos: San Sebastián del Oeste (SSO), municipio ubicado en el occidente de Jalisco, México, cuenta con inventarios de flora y micobiota realizados por varios autores del presente trabajo. Sin embargo, tales compilaciones excluyen información sobre el estado de conservación de las especies citadas. Por lo anterior, el objetivo de esta contribución es aportar datos sobre el endemismo y las categorías de riesgo de estos grupos biológicos, que coadyuven a las estrategias para su conservación.

Métodos: Se tomaron como base los listados de la flora y los hongos del municipio, y se determinó la distribución de sus especies con base en la revisión bibliográfica y bases de datos digitales. Posteriormente se definieron los niveles de endemismo. Las categorías de riesgo se determinaron mediante el cotejo de los listados mencionados con las listas de la NOM-059-SEMARNAT-2010, la Lista Roja de especies amenazadas de la UICN (LRUICN) y los apéndices de CITES. Para plantas se revisó también la Lista Roja de Árboles del Bosque Mesófilo de Montaña (LR-BMM).

Resultados clave: Se presenta un listado de 407 especies y taxones infraespecíficos de plantas vasculares. De ese listado, 332 elementos están en una o varias categorías de riesgo (38 en la NOM-059-SEMARNAT-2010, 121 en la LR-BMM, 80 en CITES y 205 en la LR-UICN) y 94 son endémicos del occidente de México. De los endémicos, 31 se restringen a Jalisco y seis son microendémicos exclusivos del municipio. En cuanto a hongos, se reconocen cinco especies en la NOM-059-SEMARNAT-2010 y cinco en la LR-UICN; no existen registros en CITES.

Conclusiones: San Sebastián del Oeste es un importante reservorio de plantas endémicas y en riesgo. El conocimiento del estado de conservación de la micobiota es más incipiente que el de las plantas.

Palabras clave: bosque mesófilo de montaña, especies cuasi endémicas, hongos, microendemismo, riesgo de extinción.

\section{Abstract:}

Background and Aims: Inventories of flora and mycobiota of the municipality San Sebastián del Oeste (SSO) located in western Jalisco, Mexico, have already been published by several authors of this work. However, these compilations exclude specific information regarding the conservation status of the cited species. The objective of this contribution is to provide data regarding the endemism and risk categories of these biological groups, which could contribute to strategies for their conservation.

Methods: The published lists of the flora and fungi of the municipality were used as a base. Distributions of the species were determined after review of literature and digital databases. Subsequently the levels of endemism were defined. The risk categories were designated by comparing both mentioned lists, with those of the NOM-059-SEMARNAT-2010, the IUCN Red List of Threatened Species (LR-IUCN) and the CITES appendices. For plants, the Red List of Mexican cloud forest trees (LR-BMM) was also consulted.

Key results: A list of 407 vascular plant species and infraspecific taxa is presented. Of that list, 332 elements are in one or more risk categories (38 in NOM-059-SEMARNAT-2010, 121 in LR-BMM, 80 in CITES and 205 in LR-IUCN). Additionally, 94 are endemic to western Mexico, of which 31 are restricted to Jalisco and of these, six are micro-endemics, exclusive to the municipality. Regarding fungi, five species are recognized in the NOM-059SEMARNAT-2010 and five in the LR-IUCN. There are no CITES records for the fungi.

Conclusions: San Sebastián del Oeste is an important reservoir of endemic and threatened plants. The knowledge of the conservation status of the mycobiota is more incipient than in plants.

Key words: cloud forest, extinction risk, fungi, microendemism, near endemic species.

'Universidad de Guadalajara, Centro Universitario de Ciencias Biológicas y Agropecuarias (CUCBA), Departamento de Botánica y Zoología, Apdo. postal 1-139, 45101 Zapopan, Jalisco México.

${ }^{2}$ Autora para la correspondencia: olivia.rodriguez@academicos.udg.mx
Recibido: 31 de julio de 2020.

Revisado: 15 de septiembre de 2020

Aceptado por Marie-Stéphanie Samain: 30 de octubre de 2020.

Publicado Primero en línea: 27 de noviembre de 2020. Publicado: Acta Botanica Mexicana 128(2021).
Citar como: Hernández-López, L., O. Rodríguez-Alcántar, D. Figueroa-García, J. J. Reynoso-Dueñas y A. Arias. 2020(2021). Flora y micobiota en riesgo y endémicas en el municipio San Sebastián del Oeste, Jalisco, México. Acta Botanica Mexicana 128: e1771. DOI: https://doi.org/10.21829/abm128.2021.1771 cc) (i) (8) Este es un artículo de acceso abierto bajo la licencia Creative Commons 4.0 Atribución-No Comercial (CC BY-NC 4.0 Internacional). 


\section{Introducción}

En las últimas décadas se ha promovido un mayor reconocimiento de la importancia que la diversidad biológica tiene en nuestro desarrollo y evolución como especie (Wilson, 1988, 1998). Numerosos trabajos enfatizan cómo los bienes y servicios que proporciona la biodiversidad son fundamentales para nuestra sobrevivencia y bienestar (Wilson, 1988; MEA, 2005; Sarukhán et al., 2017). No obstante, a pesar de la creciente apreciación de la biodiversidad, la presión que las actividades humanas ejercen sobre esta es cada vez mayor. Estudios recientes muestran que la pérdida de esa diversidad a nivel mundial ocurre de forma acelerada y a una tasa sin precedente en la historia de la humanidad; ya que un millón de especies se encuentran amenazadas de extinción, lo cual se considera alarmante. Las causas se atribuyen principalmente a la acción humana directa o indirecta (IPBES, 2019).

En el ámbito mundial existen numerosas estrategias que inciden en la problemática mencionada. La identificación del estado de conservación de las especies constituye una herramienta fundamental para plantear acciones y prioridades para su protección, de ahí que la Unión Internacional para la Conservación de la Naturaleza (UICN) (UICN, 2020) destaque como un organismo pionero y líder en la evaluación e identificación de especies en riesgo. Por medio de su Comisión de Supervivencia de Especies y del uso de métodos claramente definidos se generan las Listas Rojas de especies amenazadas; a su vez se agrupan en ocho categorías (UICN, 2020). Las especies organizadas en las siguientes categorías: En Peligro Crítico (CR), En Peligro (EN) o Vulnerable (VU), se consideran de manera genérica como amenazadas; es decir, son "especies susceptibles de extinguirse en un futuro próximo"; mientras que Casi Amenazada (NT) y Preocupación Menor (LC) reflejan que el riesgo al que están sujetas es menor (UICN, 2020).

Por otra parte, las especies reguladas por la Convención sobre el Comercio Internacional de Especies Amenazadas de Fauna y Flora Silvestres (CITES), acuerdo internacional entre gobiernos, se presentan en tres apéndices según la amenaza que enfrenten por su comercio. El Apéndice l es el que incluye a las de mayor riesgo y de forma descendente, los otros dos (CITES, 2019).
En concordancia con las tendencias internacionales, México cuenta con un Comité que impulsa en su territorio la misión de la UICN, forma parte de la CITES - donde registra 2538 especies en sus apéndices (CITES, 2019)- y publica la Norma Oficial Mexicana 059 (SEMARNAT, 2010), que constituye el instrumento legal para la protección de especies nativas de flora y fauna en riesgo. Esta Norma proporciona una lista propia establecida en cuatro categorías definidas con base en el método de evaluación del riesgo de extinción de especies silvestres en México (MER); a la fecha documenta casi 2600 especies (CONABIO, 2020). Así mismo, dispone de una Lista Roja de Árboles del Bosque Mesófilo de Montaña (González-Espinosa et al., 2011) que emplea las mismas categorías de riesgo de la UICN. Esta Lista incluye 762 especies arbóreas que se desarrollan en esa comunidad vegetal, sinecia reconocida por su alta riqueza y endemismo florístico en nuestro país (Rzedowski, 1996; CONABIO, 2010; Villaseñor, 2010).

La participación de México en las iniciativas mencionadas es pertinente y justificada, ya que forma parte del selecto grupo de países que albergan una alta diversidad y endemismo, una gran variedad de ecosistemas terrestres y acuáticos y una notable riqueza cultural. Se estima que en su territorio se encuentra entre 10 y $12 \%$ de las especies del mundo (Llorente-Bousquets y Ocegueda, 2008; Sarukhán et al., 2017; Koleff et al., 2019). Según las estimaciones de Christenhusz y Byng (2016), la diversidad de la flora vascular consta de 308,312 especies a nivel mundial; México se posiciona en el cuarto lugar al reconocer 23,300, de las cuales cerca de $50 \%$ son endémicas (Villaseñor, 2016). A pesar de ello, en las últimas cinco décadas los ecosistemas, y la biodiversidad del país en general, se han visto impactados por la actividad humana; en 2011 la superficie de bosque primario representaba $50 \%$ de su cobertura original, mientras que la de selvas y bosques era de $32 \%$, con mayores pérdidas en zonas tropicales (Sarukhán et al., 2017).

En cuanto a los hongos, el conocimiento sobre su biodiversidad a escala mundial es menor comparado con el de las plantas vasculares. Las estimaciones recientes sobre el número de especies fúngicas varían de 2.2 a 3.8 miIlones (Mueller et al., 2007; Hawksworth y Lücking, 2017; Larsen et al., 2017), de acuerdo con parámetros principal- 
mente ecológicos y biogeográficos como los abordados por Hawksworth (1991) y Guzmán $(1995,1998)$. Este último estimó entre 120,000 y 200,000 especies para México; donde se tiene un registro aproximado de 6500 taxones de macromicetos, principalmente (Aguirre-Acosta et al., 2014).

Los listados de macromicetos y sus análisis ecológicos muestran una relación entre la diversidad fúngica y el buen estado de conservación de los ecosistemas (Heilmann-Clausen y Christensen, 2003). No obstante, la destrucción de estos por la tala inmoderada, los incendios, la erosión del suelo o la apertura de zonas para cultivo o de carreteras, han ocasionado que diversas especies fúngicas se encuentren amenazadas, en peligro o extintas (Vovides et al., 1997).

Pocos son los trabajos que abordan el endemismo de hongos o áreas de endemismo en México. En uno de ellos, Vovides et al. (1997) presentan una relación de plantas y hongos raros mexicanos - amenazados o en peligro de extinción- en diferentes tipos de vegetación; de acuerdo con las categorías de la Lista Roja de la UICN. Por otra parte, Cifuentes et al. (2004) abordan la distribución de macromicetos, para la identificación del endemismo en la Sierra Madre Oriental, a partir de listados fungísticos. Este tipo de trabajos resulta relevante ante los retos de conservación de la biodiversidad en general y de los hongos en particular (Courtecuisse, 2001).

Jalisco es un estado de la República Mexicana que, por su riqueza florística - cuantificada entre 7155 (Villaseñor, 2016) y 7483 taxones de plantas vasculares (RamírezDelgadillo et al., 2010)-, ocupa la cuarta posición en el país. En cuanto al endemismo registra el segundo lugar (ViIlaseñor, 2016). Si se analiza por grupos taxonómicos destaca en primer lugar nacional por su endemismo en Lamiaceae, Asteraceae y Poaceae (Martínez-Gordillo et al., 2017; Villaseñor, 2018; Sánchez-Ken, 2019).

Al interior del estado, la porción occidental -en la que se sitúa el municipio San Sebastián del Oeste (SSO)-, se ha reconocido como una de las áreas relevantes por su biodiversidad y endemismo. Existen varios trabajos que documentan la flora del área; algunos se han enfocado a ciertos sitios dentro de la entidad (Reynoso-Dueñas, 2004) y otros han abarcado gran parte de su territorio (ReynosoDueñas et al., 2006; Harker et al., 2017). Harker et al. (2017) registran 1225 especies incluidas en 564 géneros y 162 fa- milias de plantas vasculares. Para la micobiota, Rodríguez et al. (2019) citan 311 especies de hongos y hacen patente la necesidad de continuar los trabajos micológicos para documentar mejor la diversidad de este grupo biológico.

San Sebastián del Oeste también forma parte de uno de los centros de endemismo florístico identificados en Jalisco por Hernández-López (1995) -quien toma en cuenta varias familias de plantas vasculares - y por aquellos que han realizado trabajos en torno a grupos taxonómicos particulares, como es el caso de la familia Asteraceae (Villaseñor, 1991) y el género Cosmos Cav. (Asteraceae) (VargasAmado et al., 2013, 2019).

Desde la perspectiva de la conservación de la biodiversidad, la mayor parte del territorio del municipio forma parte del Área de Protección de Recursos Naturales de la Cuenca Alimentadora del Distrito Nacional de Riego 043, fracción Sierra de Vallejo-Río Ameca (CONANP, 2020), y también se incluye en la Región Terrestre Prioritaria 62 Sierra de Vallejo-Río Ameca (CONABIO, 2004). A escala regional, otra iniciativa para la conservación $-y$ que incluye el municipio SSO - fue la propuesta de Reserva de la Biosfera realizada por Vázquez et al. (2000a), la cual; sin embargo, no llegó a consolidarse. Por otra parte, Reynoso-Dueñas (2004) realizó un estudio en el municipio, en dos sitios con bosque mesófilo de montaña y registró 15 especies en alguna categoría de la NOM-059 (SEMARNAT, 2002) vigente en ese tiempo.

A medida que el impacto sobre los hábitats naturales se incrementa, el área de distribución y el tamaño poblacional de numerosas especies se reducen; aumentando así la probabilidad de que se extingan. Aquellas especies que de manera intrínseca tienen áreas de distribución restringida - como las endémicas-, poseen requerimientos específicos de hábitat o son sensibles a cambios ambientales, son especialmente vulnerables a la extinción (Isaac y Cowlishaw, 2004; Ricketts et al., 2005); de ahí el interés de generar información que coadyuve a las acciones de conservación de la biota.

Algunos autores del presente trabajo colaboraron en la actualización del inventario florístico (Harker et al., 2017) y micológico (Rodríguez et al., 2019) del municipio, pero excluyeron el estado de conservación de las especies. Dada la importancia que tal información tiene en estrategias de 
conservación, la presente contribución tiene como objetivo enlistar las especies de la flora y micobiota de SSO, que están en alguna categoría de riesgo, y aquellas con algún nivel de endemismo.

\section{Materiales y Métodos}

\section{Área de estudio}

El municipio San Sebastián del Oeste (SSO) se ubica en el oeste del estado de Jalisco, entre las coordenadas $20^{\circ} 39^{\prime} 45^{\prime \prime}$ y $21^{\circ} 02^{\prime} 30^{\prime \prime}$ de latitud norte y $104^{\circ} 35^{\prime} 00^{\prime \prime}$ y $104^{\circ} 51^{\prime} 00^{\prime \prime}$ de longitud oeste; abarca una superficie de 140,013 ha. Limita al norte con el estado de Nayarit, al este con el municipio Guachinango, al sur con el de Mascota y al oeste con el de Puerto Vallarta (Fig. 1). Presenta una topografía accidentada en la mayor parte de su superficie y un intervalo de elevación entre 300 y 2500 m. La temperatura media anual es de $20.9{ }^{\circ} \mathrm{C}$, máxima de $32.5^{\circ} \mathrm{C}$ y mínima de $7.9^{\circ} \mathrm{C}$; con régimen de lluvias en los meses de junio a octubre y un promedio de 15 días al año con heladas. La precipitación anual es de 980 a 1441 mm (INAFED, 2010; CONABIO et al., 2020). Existen algunos arroyos de caudal permanente que, en conjunto con los ríos Ameca y Los Reyes, conforman la Cuenca Hidrológica Río Ameca. Los principales tipos de suelo corresponden a los Feozem háplico, Vertisol crómico y Cambisol eútrico (INAFED, 2010). Desde el punto de vista biogeográfico; con base en la regionalización de Morrone et al. (2017), el municipio forma parte de tres provincias: Costa Pacífica Mexicana, Sierra Madre del Sur y Eje Volcánico Transmexicano.

San Sebastián del Oeste, de acuerdo con Rzedowski (1978), presenta los siguientes tipos de vegetación: bosque de pino, bosque de pino-encino, encinar, bosque tropical caducifolio, bosque tropical subcaducifolio, bosque mesófilo de montaña, bosque de Abies y vegetación acuática y subacuática. En cuanto a la flora, registra 1225 especies incluidas en 564 géneros y 162 familias de plantas vasculares (Harker et al., 2017); respecto a su micobiota, están catalogadas 311 especies en 165 géneros y 66 familias (Rodríguez et al., 2019).

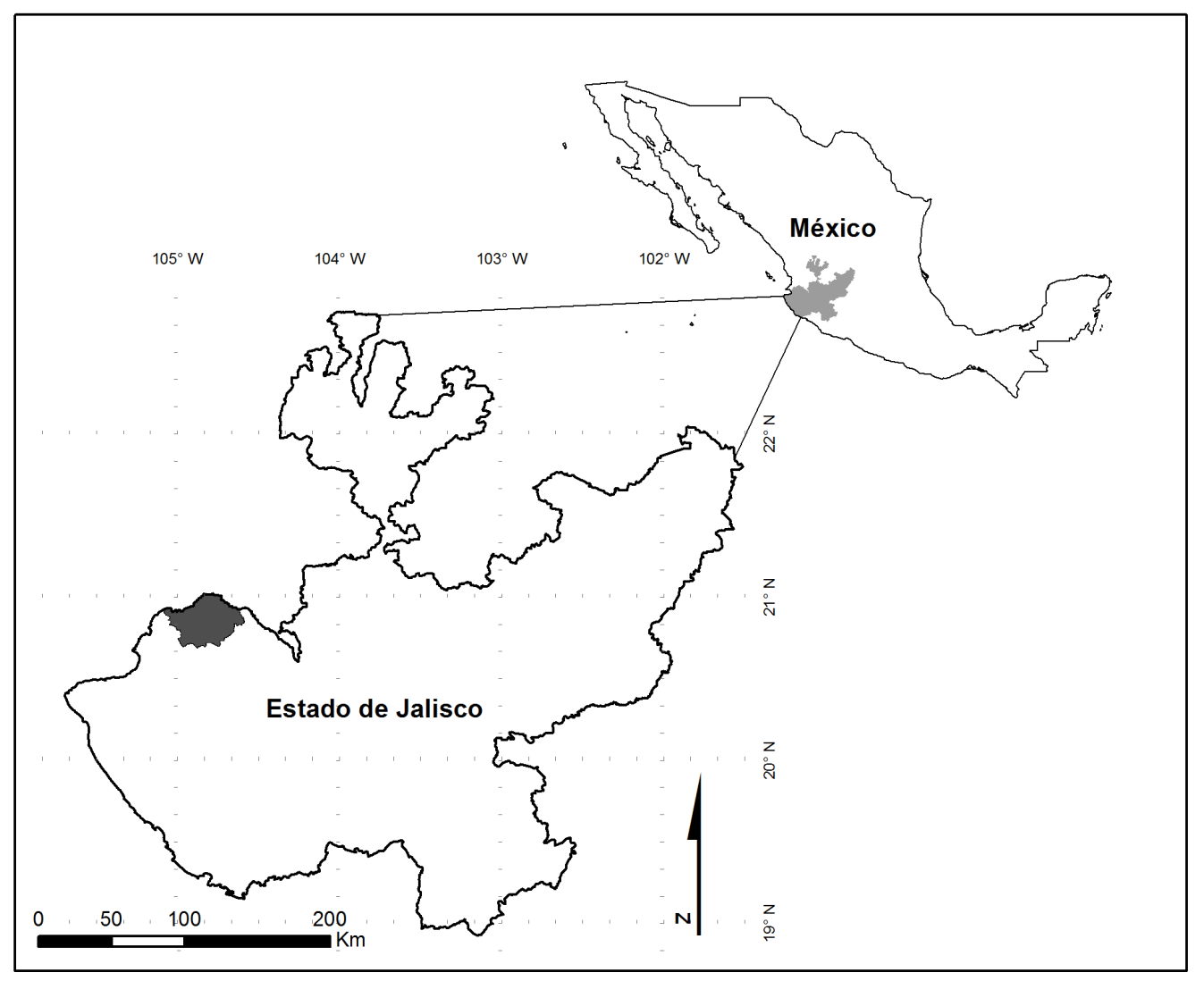

Figura 1: Ubicación geográfica del municipio San Sebastián del Oeste, Jalisco, México. 


\section{Obtención de datos}

Para determinar el elemento endémico en la flora del municipio se tomó como base el listado de Harker et al. (2017), que es el que registra más recientemente las especies presentes en la entidad. Se determinó la distribución geográfica de estas mediante la revisión exhaustiva de trabajos monográficos y de catálogos florísticos. Entre los de alcance local están el de Reynoso-Dueñas (2004) y Reynoso-Dueñas et al. (2006); a escala regional los de Ramírez-Delgadillo y Reynoso-Dueñas (2000), González-Gallegos et al. (2016), ViIlaseñor (2016) y Rzedowski (2020), y a nivel nacional los de Martínez-Gordillo et al. (2017), Martínez et al. (2017), Dávila et al. (2018), Espejo-Serna y López-Ferrari (2018), González-Elizondo et al. (2018) y Sánchez-Ken (2019). También se revisaron los registros de las bases de datos disponibles en la Red Mundial de Información sobre Biodiversidad (REMIB, 2020) de la Comisión Nacional para el Conocimiento y Uso de la Biodiversidad (CONABIO); en particular, la de especies endémicas de Jalisco de Hernández-López (2019), la cual se actualizó mediante revisión bibliográfica. Además, se consultó la colección del Instituto de Biología de la Universidad Nacional Autónoma de México (IBDATA, 2020) y la Global Biodiversity Information Facility (GBIF, 2020), para grupos selectos de especies. Asimismo, se revisaron publicaciones recientes que aportan nuevos registros o descripción de especies nuevas para la flora del área, como los de Pérez de la Rosa y Gernandt (2017), González-Villarreal (2018), Munguía-Lino et al. (2018) y Sánchez-Chávez y Zamudio (2019).

Por otra parte, las especies fúngicas incluidas para este trabajo fueron las listadas en el catálogo actual de la zona de estudio (Rodríguez et al., 2019), más las adiciones - producto de la revisión de la colección micológica del herbario IBUG-, con el fin de incluir registros nuevos. Para la obtención de información sobre endemismos se analizó la distribución geográfica de las especies; para ello, se consultaron diversos trabajos micológicos de SSO y del occidente del país en los que se incluyera material revisado del área de estudio (Pulido-Pérez, 2008; Bautista-Hernández et al., 2011; Sánchez-Jácome y Guzmán-Dávalos, 2011; Guzmán et al., 2013; Landeros y Guzmán-Dávalos, 2013; Raymundo et al., 2013; Gándara-Zamorano et al., 2014; López-Ramírez y Medel, 2016; Montañez et al., 2016; Padilla-Velarde et al., 2016; Rodríguez, 2013; Rodríguez et al., 2009, 2010a, b,
2013, 2018, 2020; Terríquez-Villanueva et al., 2017; UitzilColli y Guzmán-Dávalos, 2019) y se revisaron las bases de datos para plantas, previamente mencionadas (GBIF, 2020; IBDATA, 2020; REMIB, 2020).

Los datos sobre el estatus de riesgo fueron obtenidos del cotejo de cada especie de planta y hongo de SSO en los siguientes listados: Lista Roja de especies en riesgo de la UICN (2020), apéndices vigentes de la CITES (2019), las listas de la NOM-059 (SEMARNAT, 2010) y Anexo Normativo III de la NOM-059 (SEMARNAT, 2019), aunque en esta última no se encontraron especies para SSO. Para las plantas se revisó, además, la Lista Roja de Árboles del Bosque Mesófilo de Montaña de México (González-Espinosa et al., 2011); no obstante que en esta se emplean las mismas categorías de la UICN, aquí se hace énfasis en una comunidad vegetal particular y en una forma biológica específica.

\section{Lista de especies}

El listado de plantas se organizó con base en los siguientes sistemas de clasificación: las familias de helechos y afines, de acuerdo con Pteridophyte Phylogeny Group (PPG I, 2016). Las gimnospermas según el sistema de Byng (2015) y las angiospermas conforme a la propuesta de APG IV (APG IV, 2016; Byng et al., 2018). En cada grupo, las familias, géneros y especies se ordenaron en forma alfabética. La clasificación taxonómica y la validación de las especies fúngicas siguieron lo establecido por Wijayawardene et al. (2018), He et al. (2019), Index Fungorum (2020) y MycoBank (2020).

A las especies y taxones infraespecíficos, del listado de plantas, se les asignó su hábito tomando como base el trabajo de Harker et al. (2017), con algunas modificaciones. Se definieron los siguientes hábitos: arbóreo, arbustivo, herbáceo (terrestre, epífito y rupícola), trepador y parásito. Algunas especies pueden crecer como arbustos y como árboles pequeños. En esos casos se anotaron en el apéndice los dos hábitos, pero solo se cuantificaron una vez y se consideró el encontrado con mayor frecuencia.

Para el caso de los hongos se incluye información sobre el hábitat de los taxones en riesgo, de acuerdo con el catálogo realizado por Rodríguez et al. (2019). Se incluyen imágenes de algunas especies - de plantas y hongos - endémicas o en alguna categoría de riesgo. 
Con base en la distribución conocida de las especies se determinaron cuatro categorías de endemismo: 1) nacional, 2) occidente de México (Jalisco y estados colindantes: Aguascalientes, Colima, Durango, Guanajuato, Michoacán, Nayarit, San Luis Potosí, Zacatecas), 3) solo Jalisco y 4) municipio San Sebastián del Oeste. Las plantas endémicas de México se cuantifican en el análisis general, pero si su distribución rebasa el occidente del país no se incluyen en el listado, a excepción de presentar alguna categoría de riesgo.

\section{Resultados}

Derivado de la revisión bibliográfica y de la consulta de bases de datos se presenta el listado de plantas vasculares en riesgo y endémicas, que crecen en San Sebastián del Oeste. Este listado consta de 407 especies, y taxones infraespecífi- cos, incluidos en 253 géneros y 97 familias (Apéndice), y se detalla a continuación.

\section{Flora en riesgo de extinción}

De la flora de SSO se registran en una o varias categorías de riesgo, 332 especies (incluyendo 31 con categoría infraespecífica) pertenecientes a 216 géneros y 85 familias. Su distribución en las listas de riesgo es la siguiente: en la NOM-059 se encuentran 38, 121 están en la Lista Roja de Árboles del Bosque Mesófilo de Montaña (LR-BMM); en los listados internacionales se registran 80 en los apéndices del CITES y 205 en la Lista Roja de la UICN (LR-UICN) (Apéndice, Cuadro 1, Fig. 2).

Las categorías de riesgo que incluyen el mayor número de especies y jerarquías infraespecíficas son las siguientes: Preocupación menor (LC) de la LR-UICN, 177; Apéndice

Cuadro 1: Categorías de riesgo que presenta la flora de San Sebastián del Oeste (SSO), Jalisco, México, en cuatro listas de riesgo.

\begin{tabular}{|c|c|}
\hline Categorías de riesgo & Número de taxones \\
\hline \multicolumn{2}{|l|}{ NOM-059 } \\
\hline Probablemente extinta en el medio silvestre (E) & 0 \\
\hline En peligro de extinción (P) & 8 \\
\hline Amenazada (A) & 14 \\
\hline Sujeta a protección especial (Pr) & 16 \\
\hline Total & 38 \\
\hline \multicolumn{2}{|l|}{ Lista Roja de árboles BMM (LR-BMM) } \\
\hline En peligro crítico (CR) & 2 \\
\hline En peligro (EN) & 15 \\
\hline Vulnerable (VU) & 21 \\
\hline Casi amenazada (NT) & 15 \\
\hline Preocupación menor (LC) & 68 \\
\hline Total & 121 \\
\hline \multicolumn{2}{|l|}{ CITES } \\
\hline Apéndice I & 1 \\
\hline Apéndice II & 79 \\
\hline Total & 80 \\
\hline \multicolumn{2}{|l|}{ Lista Roja de la UICN (LR-UICN) } \\
\hline Extinto en Estado Silvestre (EW) & 0 \\
\hline En peligro crítico $(\mathrm{CR})$ & 0 \\
\hline En peligro (EN) & 7 \\
\hline Vulnerable (VU) & 14 \\
\hline Casi amenazado (NT) & 7 \\
\hline Preocupación menor (LC) & 177 \\
\hline Total & 205 \\
\hline
\end{tabular}




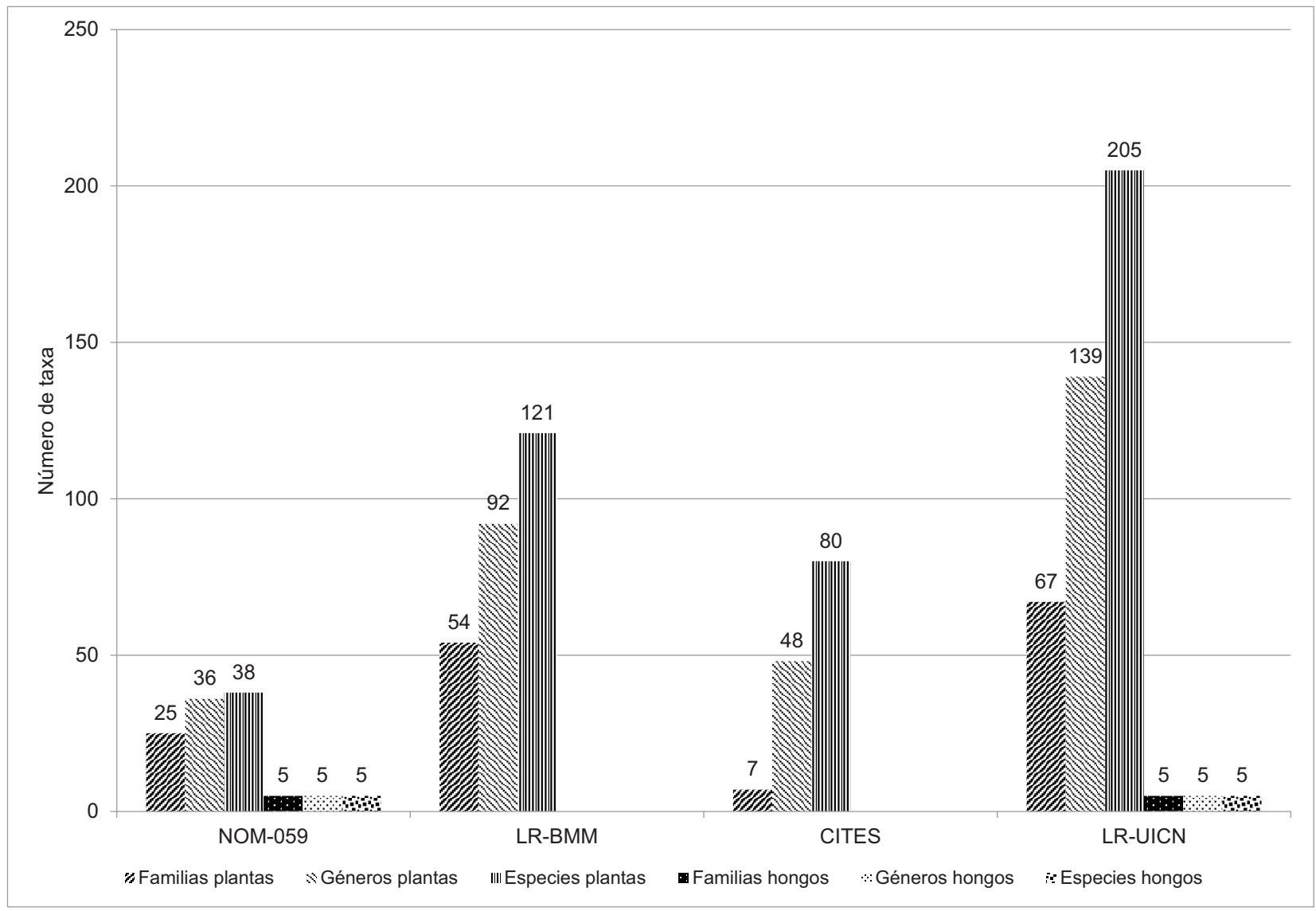

Figura 2: Cuantificación de la flora y micobiota de San Sebastián del Oeste, Jalisco, México, que se encuentra en riesgo en los diferentes instrumentos analizados: NOM-059-SEMARNAT-2010, Lista Roja de árboles del bosque mesófilo de montaña (LR-BMM), CITES, Lista Roja de la Unión Internacional para la Conservación de la Naturaleza (LR-UICN).

II del CITES, 79; Preocupación menor (LC) y Vulnerable (VU) - ambas de la LR-BMM-, 68 y 21, respectivamente (Cuadro 1). Si se cuantifican solo aquellas en las categorías que representan mayor amenaza - En peligro crítico, En peligro y Vulnerable-, suman 82 (24.7\% de las listadas en riesgo). De ellas, la LR-BMM contiene el mayor número con 38; la NOM-059, 22; la LR-UICN, 21 y el Apéndice I del CITES, solo una.

Los grupos taxonómicos de la flora de SSO que se encuentran en riesgo y los diferentes niveles de endemismo, se muestran en el cuadro 2. Respecto al estado de riesgo se observa que las angiospermas, en particular las eudicotiledóneas, concentran el mayor número de elementos: LRUICN, 166; LR-BMM, 110; NOM-059, 20 y ocho en CITES. Le siguen las monocotiledóneas con 68 en CITES, 16 en LRUICN y 10 en la NOM-059. Son 16 familias las que contienen el mayor número (214) de especies y categorías infraespecíficas en riesgo, lo que representa $64.4 \%$ (Cuadro 3 ).
Destacan Orchidaceae $(68,20.5 \%)$, Fabaceae $(35,10.5 \%)$, Fagaceae $(19,5.7 \%)$ y Rubiaceae $(10,3 \%)$; mientras que los géneros que sobresalen son Quercus L. (19), Habenaria Willd. (11) y Phaseolus L. (7) (Apéndice).

Si por cada instrumento revisado se analiza la composición de especies, subespecies y variedades, de las familias de la flora del municipio, los resultados son: en CITES sobresalen Orchidaceae (85\%), Cactaceae (7.5\%) y Zamiaceae (2.5\%); en la LR-BMM predominan Fagaceae, Primulaceae, Rosaceae y Rubiaceae (6 elementos cada una), y Salicaceae (5); en la LR-UICN destacan Fabaceae (35), Fagaceae (19) y Poaceae (9), y en la NOM-059 se enlistan ocho componentes de Orchidaceae, mientras que 24 familias tienen solo uno o dos elementos (Apéndice).

Del total de especies y categorías infraespecíficas en riesgo, Abies guatemalensis Rehder var. jaliscana Martínez aparece en los cuatro listados revisados (NOM-059, CITES, LR-BMM y LR-UICN), 16 elementos se encuentran en tres 
Cuadro 2: Grupos taxonómicos de la flora de San Sebastián del Oeste (SSO), Jalisco, México, especies y categorías infraespecíficas incluidas en las listas de riesgo y endemismo que presentan a diferentes escalas. *Incluye Jalisco y estados colindantes, pero se muestran por separado los datos para Jalisco y el municipio de SSO para enfatizar la importancia del área de estudio.

\begin{tabular}{|c|c|c|c|c|c|c|c|c|}
\hline \multirow[b]{2}{*}{ Grupo taxonómico } & \multicolumn{4}{|c|}{ Riesgo } & \multicolumn{4}{|c|}{ Endemismo } \\
\hline & NOM-059 & LR-BMM & CITES & LR-UICN & sso & Jalisco & Occidente* & México \\
\hline \multicolumn{9}{|l|}{ HELECHOS } \\
\hline Polypodiidae & 2 & & 1 & 3 & & & 1 & 5 \\
\hline \multicolumn{9}{|l|}{ GIMNOSPERMAS } \\
\hline Cycadidae & 2 & & 2 & 2 & & & & 1 \\
\hline Pinidae & 4 & 5 & 1 & 11 & & 2 & 1 & 4 \\
\hline \multicolumn{9}{|l|}{ ANGIOSPERMAS } \\
\hline Magnólidas & & 6 & & 7 & & 1 & 6 & 17 \\
\hline Monocotiledóneas & 10 & & 68 & 16 & 1 & 2 & 7 & 72 \\
\hline Eudicotiledóneas & 20 & 110 & 8 & 166 & 5 & 20 & 48 & 366 \\
\hline TOTAL & 38 & 121 & 80 & 205 & 6 & 25 & 63 & 465 \\
\hline
\end{tabular}

Cuadro 3: Familias con mayor número de especies, y taxones infraespecíficos en riesgo y sus géneros representativos en la flora de San Sebastián del Oeste (SSO), Jalisco, México.

\begin{tabular}{lcl}
\hline Familias & Número de taxones & Géneros representativos \\
\hline Orchidaceae & 68 & Habenaria Willd. \\
Fabaceae & 35 & Phaseolus L., Senna Mill. \\
Fagaceae & 19 & Quercus L. \\
Rubiaceae & 10 & Randia L. \\
Poaceae & 9 & Aegopogon Humb. \& Bonpl. ex Willd., Paspalum L. \\
Asteraceae & 8 & Acourtia D. Don, Ageratina Spach \\
Pinaceae & 8 & Pinus L. \\
Solanaceae & 8 & Solanum L. \\
Moraceae & 7 & Ficus L. \\
Primulaceae & 7 & Ardisia Sw., Myrsine L. \\
Apocynaceae & 6 & Tabernaemontana L. \\
Cactaceae & 6 & Opuntia Mill. \\
Rosaceae & 6 & Prunus L., Photinia Lindl. \\
Salicaceae & 6 & Casearia Jacq., Xylosma Forst. \\
Urticaceae & 6 & Urera Gaudich. \\
Myrtaceae & 5 & Eugenia L. \\
\hline Total & $\mathbf{2 1 4}$ & \\
\hline
\end{tabular}


listados y pertenecen a 14 familias (Cuadro 4), 77 taxones se registran en dos y el resto (238) al menos en uno (Apéndice).

En cuanto al tipo de vegetación en los que se distribuyen las especies y taxones infraespecíficos en todas las categorías de riesgo, 37\% (122) crece en el bosque mesófilo de montaña; el resto, en el bosque de pino y bosque mixto de pino y encino. Tienen hábito arbóreo 156 (47\%), 95 (28.6\%) herbáceo (50 terrestre, 43 epífito, 1 rupícola), 66 (20\%) arbustivo y 15 (4\%) trepador (Fig. 3A).

\section{Flora endémica}

De la flora endémica de México, 465 taxones específicos e infraespecíficos se encuentran en San Sebastián del Oeste y 313 de ellos se distribuyen también en otras áreas del país. Por lo anterior, en este trabajo se hace énfasis en 94 taxones (incluidas categorías infraespecíficas) que restringen su distribución al occidente de México; es decir, Jalisco y estados adyacentes: 31 se registran de Jalisco y más de uno de los estados circundantes, 32 se conocen solo de Jalisco y solo uno de los estados circundantes - ya sea Jalisco y Colima o Jalisco y Michoacán o Jalisco y Nayarit-, y se consideran cuasi endémicas de Jalisco, otros 31 son exclusivos de esta última entidad e incluyen los siguientes seis microendemismos que solo se conocen de SSO: Abutilon jaliscanum Standl. (Malvaceae), Acourtia mexiae L. Cabrera (Asteraceae), Cuphea mexiae Bacig. (Lythraceae), Desmodium saxatile (Morton) B.G. Schub. \& McVaugh (Fa-

Cuadro 4: Taxones considerados con mayor riesgo en la flora de San Sebastián del Oeste (SSO), Jalisco, México. Categorías: NOM059 (En peligro de extinción=P, Amenazada=A, Protección Especial=Pr); CITES (Apéndices I y II); LR-UICN y LR-BMM (En peligro=EN, Vulnerable=VU, Casi amenazado=NT, Preocupación menor=LC).

\begin{tabular}{|c|c|c|c|c|c|}
\hline Grupo taxonómico & Taxones & NOM-059 & LR-BMM & CITES & LR-UICN \\
\hline \multicolumn{6}{|l|}{ GIMNOSPERMAS } \\
\hline \multicolumn{6}{|l|}{ Cycadidae } \\
\hline Zamiaceae & Dioon tomasellii De Luca, Sabato \& Vázq. Torres & $P$ & & II & Vu \\
\hline Zamiaceae & Zamia loddigesii Miq. & A & & II & NT \\
\hline \multicolumn{6}{|l|}{ Pinidae } \\
\hline Cupressaceae & Cupressus lusitanica Mill. subsp. benthamii (Endl.) Franco & $\operatorname{Pr}$ & LC & & NT \\
\hline Pinaceae & Abies guatemalensis Rehder var. jaliscana Martínez & $\operatorname{Pr}$ & VU & I & NT \\
\hline Podocarpaceae & Podocarpus matudae Lundell & $\operatorname{Pr}$ & EN & & VU \\
\hline \multicolumn{6}{|l|}{ ANGIOSPERMAS } \\
\hline \multicolumn{6}{|l|}{ Monocotiledóneas } \\
\hline Orchidaceae & Cypripedium irapeanum Lex. & A & & II & VU \\
\hline Orchidaceae & Oncidium ensatum Lindl. & $\operatorname{Pr}$ & & ॥ & LC \\
\hline \multicolumn{6}{|l|}{ Eudicotiledóneas } \\
\hline Actinidiaceae & Saurauia serrata DC. & $\operatorname{Pr}$ & VU & & EN \\
\hline Betulaceae & Carpinus tropicalis (Donn. Sm.) Lundell & A & NT & & LC \\
\hline Betulaceae & Ostrya virginiana (Mill.) K. Koch & $\operatorname{Pr}$ & NT & & LC \\
\hline Cactaceae & Selenicereus atropilosus Kimnach & $\operatorname{Pr}$ & & $॥$ & EN \\
\hline Ericaceae & Comarostaphylis discolor (Hook.) Diggs subsp. discolor & $\operatorname{Pr}$ & LC & & $\mathrm{LR} / \mathrm{LC}$ \\
\hline Hamamelidaceae & Matudaea trinervia Lundell & A & VU & & VU \\
\hline Malvaceae & Tilia americana L. var. mexicana (Schltdl.) Hardin & $\mathrm{P}$ & VU & & LC \\
\hline Meliaceae & Cedrela odorata L. & $\operatorname{Pr}$ & & II & VU \\
\hline Salicaceae & Populus guzmanantlensis A.Vázquez \& Cuevas & $\operatorname{Pr}$ & VU & & EN \\
\hline Zygophyllaceae & Guaiacum coulteri A. Gray & $A$ & & ॥ & Vu \\
\hline
\end{tabular}



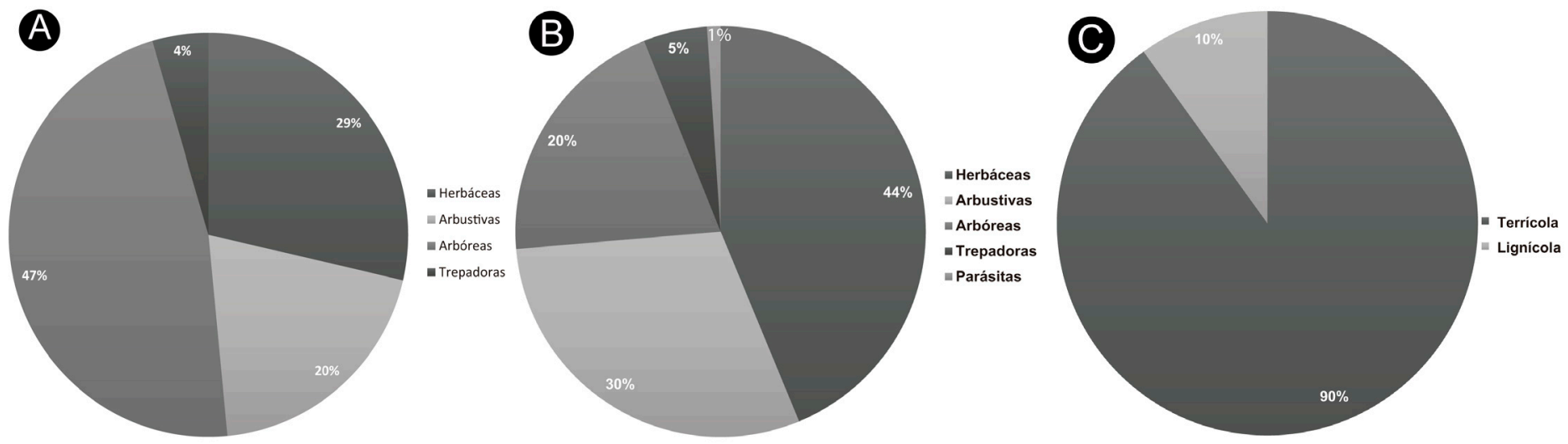

Figura 3: A. hábito de plantas en riesgo; B. hábito de las plantas endémicas; C. hábitat de hongos en riesgo y endémicos de San Sebastián del Oeste, Jalisco, México.

baceae), Eugenia harkerae E. Sánchez-Chávez \& Zamudio (Myrtaceae) y Habenaria sebastianensis R. González \& Cuev.-Fig. (Orchidaceae) (Apéndice, Cuadro 2). También se aprecian algunas disyunciones geográficas como el caso de Didymaea linearis Standl. y Habenaria agapitae R. González \& Reynoso, con distribución en Jalisco y Oaxaca, y Lepechinia glomerata Epling de Jalisco y Guerrero, entre otras. Además, casi 20 taxones se distribuyen de forma más o menos continua en la vertiente del Pacífico.

Respecto a la composición taxonómica de los taxones endémicos, el cuadro 2 muestra la distribución entre los grupos generales. De los 465 taxones y categorías infraespecíficas endémicos de México -y presentes en el municipio San Sebastián del Oeste-, la mayoría (366) están incluidos en eudicotiledóneas. Destacan las familias Asteraceae (101), Fabaceae (57), Orchidaceae (39) y Lamiaceae (30). Por otro lado, el endemismo a nivel del occidente de México y escalas geográficas menores está representado por 94 taxones que corresponden a 68 géneros y 38 familias. Destacan Asteraceae y Fabaceae al incluir el mayor número de taxones y géneros, con $19 / 11$ y $12 / 8$ cada una, respectivamente; seguidas de Lamiaceae $10 / 4$ y Orchidaceae 6/6; mientras que, por otra parte, 24 familias están representadas por un taxón (Apéndice). Los géneros mejor representados son Salvia L., con siete taxones, y Ageratina Spach y Desmodium Desv., con cuatro cada uno.

En cuanto al hábito de los 94 taxones endémicos presentes en SSO (incluidas las endémicas del occidente, las cuasi endémicas, las de Jalisco y las microendémicas), se registran 41 (44\%) con hábito herbáceo (37 terrestres y cuatro epífitas), 28 (30\%) arbustivo, 19 (20\%) arbóreo, cinco $(5 \%)$ trepador y una parásita (1\%) (Fig. 3B, 4).

De las 94 endémicas del occidente presentes en el municipio, 19 están registradas con alguna categoría de riesgo (Apéndice). Solo una de las seis especies microendémicas está listada en CITES. Por otra parte, 223 (67\%) de los 332 taxones en riesgo aquí registrados, no son endémicos de México.

\section{Hongos en riesgo y endémicos}

Con base en los datos de distribución de las especies, obtenidos de la información generada del listado fúngico del área de estudio y de lo encontrado en la entidad y región occidente, se presentan las especies que se hallan en algún estatus de riesgo.

De acuerdo con la NOM-059, se tienen 46 especies fúngicas para México en alguna categoría de riesgo, de las cuales cinco se registran para el municipio, cuatro de ellas están en el estatus de Amenazadas (A) y una en Protección especial (Pr). En los apéndices del CITES no hay registros de hongos; mientras que en la LR-UICN - de los 280 listados a escala mundial-, reconocen 25 de México y cinco de ellos se registran con la categoría de "preocupación menor" (LC) para San Sebastián del Oeste (Cuadro 5, Fig. 2).

En cuanto a las preferencias ecológicas de los 10 taxones citados en el cuadro 5, nueve son de hábito terrícola y uno lignícola (Fig. 3C, 5); destacan por su importancia ecológica y económica, ya que todas las especies terrícolas 

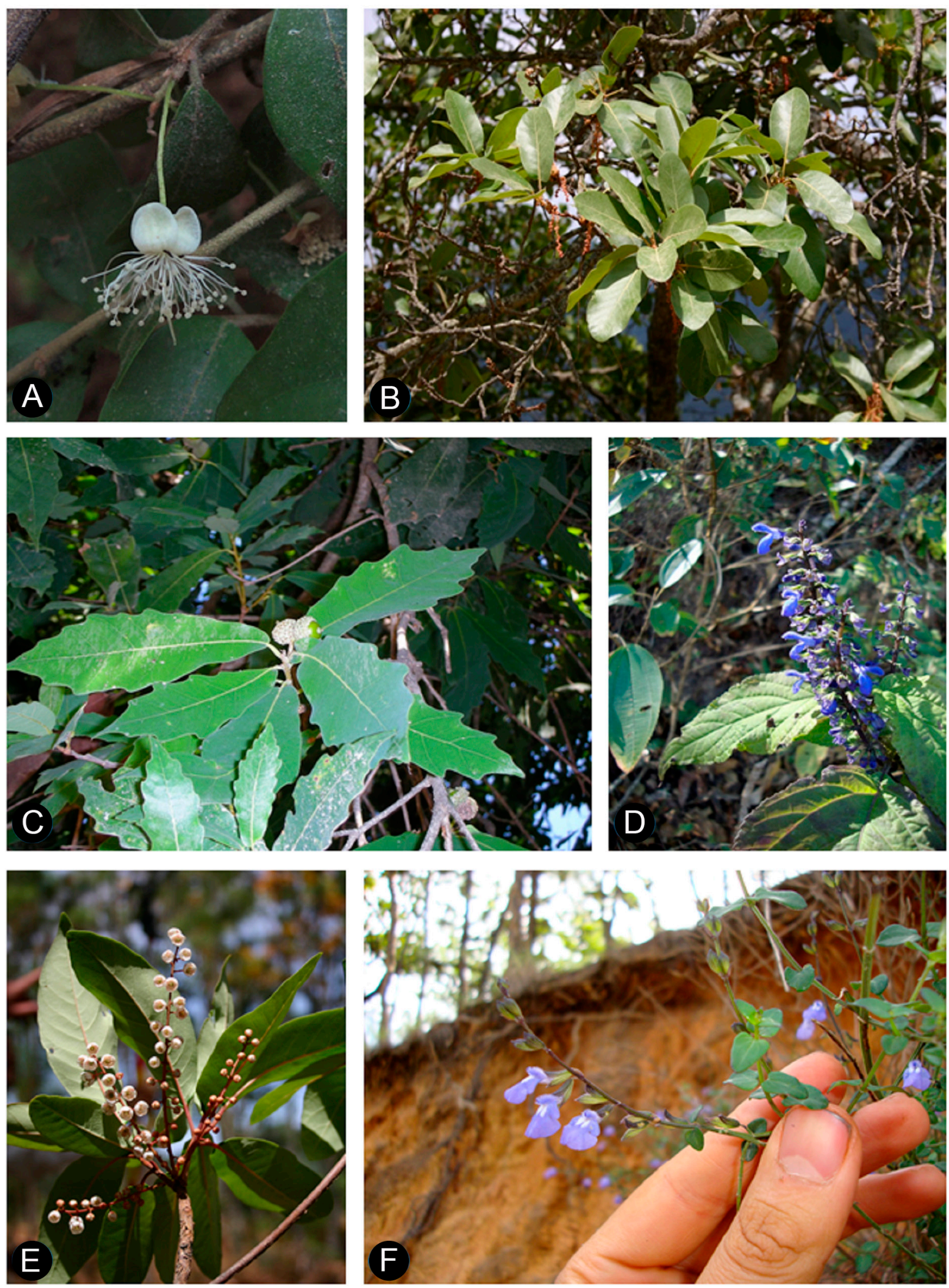

Figura 4: Muestra de plantas vasculares en riesgo y endémicas de San Sebastián del Oeste, Jalisco, México. A. Eugenia harkerae E. Sánchez-Chávez \& Zamudio; B. Quercus mexiae L.M. González; C. Quercus centenaria L.M. González; D. Salvia ibugana J.G. González; E. Clethra fragrans L.M. González \& R. Delgad.; F. Salvia ramirezii J.G. González. Fotografías de E. Sánchez Chávez (A), L. M. González Villarreal (B, C y E), J. G. González Gallegos (D y F). 
Cuadro 5: Categorías de riesgo que presentan los hongos en San Sebastián del Oeste (SSO), Jalisco, México, en cada instrumento analizado. Amenazada (A), Preocupación menor (LC) y Sujeta a protección especial (Pr). Aguascalientes (AGS), Durango (DGO), Guanajuato (GTO), Jalisco (JAL), Michoacán (MICH), Nayarit (NAY), Sal Luis Potosí (SLP), Zacatecas (ZAC).

\begin{tabular}{|c|c|c|c|c|c|}
\hline Normativa & $\begin{array}{c}\text { Total de } \\
\text { especies en } \\
\text { México }\end{array}$ & Familias & $\begin{array}{l}\text { Taxones en } \\
\text { sso }\end{array}$ & Categoría & $\begin{array}{l}\text { Distribución en occidente } \\
\text { de México }\end{array}$ \\
\hline \multirow[t]{5}{*}{ NOM-059 } & 46 & Amanitaceae & Amanita muscaria (L.) Lam. & A & DGO, GTO, JAL, MICH, NAY, SLP, ZAC \\
\hline & & Hydnaceae & Cantharellus cibarius Fr. & $\operatorname{Pr}$ & DGO, GTO, JAL, MICH, NAY \\
\hline & & Gomphidiaceae & Chroogomphus rutilus (Schaeff.) O.K. Mill. & A & DGO, JAL, MICH \\
\hline & & Hygrophoraceae & Hygrophorus russula (Schaeff. ex Fr.) Kauffman & A & DGO, GTO, JAL, MICH, ZAC \\
\hline & & Boletaceae & Leccinum aurantiacum (Bull.) Gray & A & $\mathrm{DGO}, \mathrm{JAL}, \mathrm{MICH}$ \\
\hline \multirow[t]{5}{*}{ LR-UICN } & 25 & Amanitaceae & Amanita complejo caesarea (Scop.) Pers. & LC & $\begin{array}{l}\text { AGS, DGO, GTO, JAL, MICH, NAY, } \\
\text { SLP, ZAC }\end{array}$ \\
\hline & & Boletaceae & Boletus reticulatus Schaeff. & LC & DGO, JAL, MICH, ZAC \\
\hline & & Hericiaceae & Hericium erinaceus (Bull.) Pers. & LC & $\mathrm{DGO}, \mathrm{JAL}, \mathrm{MICH}$ \\
\hline & & Hydnaceae & Hydnum repandum $\mathrm{L}$. & LC & DGO, JAL, MICH \\
\hline & & Boletaceae & Suillus granulatus (L.) Roussel & LC & $\mathrm{DGO}, \mathrm{JAL}, \mathrm{MICH}$ \\
\hline CITES & - & - & - & - & - \\
\hline
\end{tabular}

son micorrizógenas y comestibles silvestres, a excepción de Amanita muscaria (L.) Lam. que es tóxica. La especie lignícola, Hericium erinaceus (Bull.) Pers., es reconocida por su valor comestible y uso medicinal.

\section{Discusión}

En el inventario de la flora de San Sebastián del Oeste de Harker et al. (2017) se registran 1225 especies. Sin embargo, en el presente estudio se incluyen en el análisis tres nombres nuevos: Eugenia harkerae (Sánchez-Chávez y Zamudio, 2019), Quercus centenaria L.M. González y Q. mexiae L.M. González (González-Villarreal, 2018), especies que en el trabajo arriba mencionado se indicaron como "sp. nov.", ya que se encontraban en proceso de descripción como especies nuevas. De dicho inventario, Abies guatemalensis var. jaliscana recientemente fue nombrada como Abies jaliscana (Martínez) Mantilla, Shalisko \& A. Vázquez (Vázquez et al., 2014); aunque resulten sinónimos, en este estudio se consideran ambos nombres debido a que el primero refiere a una especie en riesgo y se requiere la actualización de la normatividad para que aparezca el nombre nuevo. También se adicionan, con base en la revisión bibliográfica, los siguientes registros nuevos: Tigridia pugana Aarón Rodr. \& Ortiz-Catedral en Munguía-Lino et al. (2018) y Sedum grandipetalum Fröd. por Aragón-Parada et al. (2019). Se incluye también a Pinus vallartensis Pérez de la Rosa \& D. Gernandt, especie sin registro previo en el municipio, pero recolectada recién en la entidad (Pérez de la Rosa com. pers).

Las 332 especies y taxones infraespecíficos en riesgo y registradas en SSO (incluidas en 216 géneros y 85 familias) representan $27 \%$ de los taxones, $38.3 \%$ de los géneros y un poco más de la mitad de las familias (52.5\%) registradas para el municipio. La magnitud de estos datos es sobresaliente si se compara con lo encontrado en otros sitios como la Reserva de la Biosfera El Triunfo, Chiapas, con una superficie (1191.17 $\mathrm{km}^{2}$ ) comparable a la de SSO $\left(1400.13 \mathrm{~km}^{2}\right)$, donde se han registrado 244 especies en riesgo (Martínez-Camilo et al., 2012) o el municipio de Guadalcázar, San Luis Potosí, con un área casi tres veces mayor $\left(3800 \mathrm{~km}^{2}\right)$, que presenta 123 taxones con algún grado de riesgo (Torres-Colín et al., 2017). Aunque se debe hacer mención que para Chiapas solo se cuantifican cuatro de las categorías de riesgo de la UICN. Por otra parte, el número de taxones en riesgo en SSO es similar al registrado para el estado de Oaxaca (307) por Acosta-Castellanos (2002); sin embargo, en ese estudio se tomó como base la NOM059-ECOL-1994 (INE, 1994), que incluía otras categorías de 

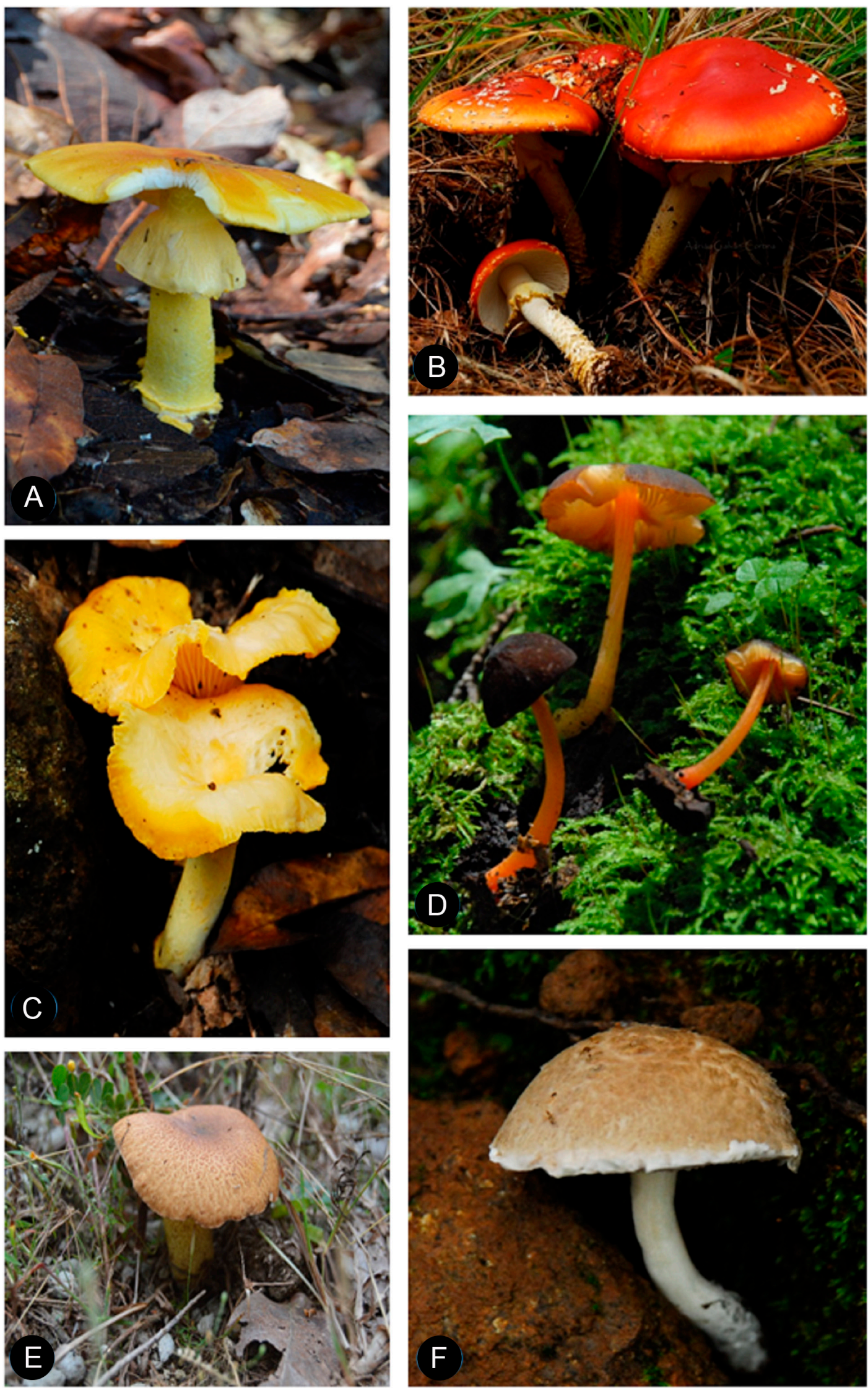

Figura 5: Esporomas de algunas especies en cierta categoría de riesgo. A. Amanita complejo caesarea (Scop.) Pers.; B. Amanita muscaria (L.) Lam.; C. Cantharellus cibarius Fr.; D. Pluteus horakianus Rodr.-Alcánt.; E. Suillus granulatus (L.) Roussel; F. Veloporphyrellus pantoleucus L.D. Gómez \& Singer. Fotografías de D. Figueroa-García (A, E) y O. Rodríguez Alcántar (B, C, D y F). 
riesgo. Es muy probable que la actualización de ese trabajo con el uso de las categorías de NOM-059 vigente, arrojará una cifra mayor, si se tiene en cuenta que Oaxaca ocupa un área muy superior a la de SSO y es el estado de mayor riqueza florística en México y el que concentra más especies endémicas (Villaseñor, 2016).

Es evidente que algunos taxones que son de gran interés han sido más estudiados y se incluyen en varios de los listados revisados; tal es el caso de las 17 especies que se encuentran en tres o más catálogos de riesgo (Cuadro 4). Esto demuestra la eminente presión que se ejerce sobre ellas, aunque también puede reflejar que se dispone de información que no existe para otros taxones. Asimismo, la composición de las familias de la flora de SSO por cada instrumento de riesgo examinado, está determinado, en parte, por los objetivos para los que fueron creados. Por ejemplo, Orchidaceae y Cactaceae son las familias que incluyen el mayor número de especies listadas en CITES. Se trata de familias con especies atractivas y de valor económico cuyo comercio precisamente CITES intenta regular, lo cual también fue observado por Vovides et al. (1997).

Por otra parte, la LR-UICN tiene un enfoque más amplio en cuanto a los grupos taxonómicos, aquí sobresalen la familia Fabaceae y el género Quercus del que es notable que de las 24 especies registradas para SSO, 19 se reconocen en la LR-UICN y tres no han sido evaluadas ya que se describieron recientemente. La LR-BMM incluye familias con afinidad por hábitats de alta humedad y generalmente son exclusivas de esos sitios, tal es el caso de Rubiaceae, Primulaceae, Rosaceae, Araliaceae, Betulaceae, Lauraceae y Chloranthaceae, entre otras. El número de especies registradas en el presente listado contrasta con el de ReynosoDueñas (2004) quien consigna solo 15 en riesgo en NOM059 en dos sitios con bosque mesófilo de montaña en el municipio.

Las especies y taxones infraespecíficos de plantas endémicas de México presentes en SSO (465) representan $38 \%$ de la flora consignada para la entidad (1225 taxones) por Harker et al. (2017) y 13.9\% de las endémicas de México registradas de Jalisco (3353) por Villaseñor (2016); no obstante, San Sebastián ocupa solo $1.7 \%$ de la superficie estatal. Asimismo, otros estudios que analizan el endemismo a escala municipal como el de Culiacán, Sinaloa, indican la presencia de 353 especies endémicas del país (Vega-Aviña et al., 2000), aunque con una superficie de más de tres veces mayor $\left(4758.9 \mathrm{~km}^{2}\right)$ que el área de estudio, lo cual destaca la relevancia de SSO.

Del endemismo nacional, Jalisco ocupa el primer lugar en Asteraceae (607 taxones), Lamiaceae (103) y Poaceae (101) (Martínez-Gordillo et al., 2017; Villaseñor, 2018; Sánchez-Ken, 2019). Sin embargo, en SSO las endémicas de México mejor representadas son Asteraceae (101), Fabaceae (57), Orchidaceae (39) y Lamiaceae (30). Una tendencia similar se aprecia en la composición taxonómica de las endémicas del occidente de México presentes en el municipio, donde Asteraceae (19), Fabaceae (12) y Lamiaceae (10) tienen el mayor número de especies. Los seis taxones exclusivos del municipio, por otra parte, se ubican en igual número de familias: Asteraceae, Fabaceae, Lythraceae, Malvaceae, Myrtaceae y Orchidaceae.

Según Villaseñor (2016), Jalisco cuenta con 182 especies endémicas exclusivas, en el presente trabajo se registran 31. Es decir, San Sebastián del Oeste alberga 16\% del endemismo estatal, incluyendo seis especies microendémicas.

Aunque el número de las especies endémicas mexicanas en el municipio es elevado (465), cerca de $20 \%$ se restringen al occidente de México y el resto se distribuyen en la vertiente del Pacífico, o hacia el centro del país, aunque no podría decirse que ocupan grandes áreas, lo que coindice con lo señalado por Villaseñor (2016). Por otra parte, es notable que, de los taxones en riesgo registrados en este trabajo, solo $33 \%$ corresponde a especies endémicas del país. De acuerdo con el trabajo de González-Espinosa et al. (2011), muchas especies del bosque mesófilo de montaña de México se distribuyen hacia Centroamérica; sin embargo, los tamaños poblacionales de estas podrían estar reducidos dado que se desarrollan en ese hábitat específico con distribución relictual.

La lista de especies en riesgo y endémicas - tanto de plantas vasculares como de hongos-, seguramente se verá incrementada a medida que se exploren áreas poco estudiadas en el municipio; tal como lo señalan, en cuanto a la riqueza florística y fúngica, otros autores (Harker et al., 2017; Rodríguez et al., 2019). Para el caso de las plantas, las áreas de cañadas y sitios de menor elevación con vegeta- 
ción tropical, además del estrato arbóreo para documentar la flora epífita, serían prioritarios para estudiar. De forma paralela, se requiere generar información sobre aspectos demográficos, ecológicos, biogeográficos y de impacto antropogénico, en las especies. Con frecuencia, la falta de datos suficientes para cubrir esos aspectos contemplados en el Método de Evaluación del Riesgo de Extinción (MER) dificulta su aplicación y, por ende, la valoración adecuada del riesgo de una especie. Si bien esta es una herramienta imprescindible para la NOM-059 y un referente en la evaluación del estado de riesgo de especies silvestres en el país, solo $9 \%$ de los taxones de plantas hasta ahora incluidos ahí han sido evaluados. Es importante tener en cuenta que los instrumentos de riesgo - nacionales e internacionales-, aunque son iniciativas loables para guiar acciones de conservación hacia las especies que incluyen, también presentan sesgos y limitaciones como la falta de actualización, además de las ya mencionadas. Por otra parte, se ha reconocido que la determinación del riesgo de las especies no necesariamente se refleja en la implementación de programas para su conservación (Whitten et al., 2001; Knight et al., 2008), por lo que se hace necesario una estrategia integrada.

La importancia biológica de SSO ha sido reconocida al integrarla a la región terrestre prioritaria Sierra de Vallejo-Río Ameca (Arriaga et al., 2000; CONABIO, 2004) y a un Área de Protección de Recursos Naturales (CONANP, 2020). Sin embargo, aunque esta última área natural protegida (ANP) cuenta con decreto de protección federal, no dispone aún de un programa de manejo y las iniciativas por parte de la Comisión Nacional de ANP (CONANP) son aisladas en la zona; entonces, las acciones de manejo y de protección de la biodiversidad son insuficientes (Jardel-Peláez et al., 2017). La efectividad de esta ANP en la conservación de la flora y de la biota en general de esta zona, tendría que evaluarse.

Recientemente (2019) surgió una iniciativa privada en el municipio para el establecimiento de Haravéri: jardín botánico in situ con superficie de 11 hectáreas que incluye bosque de pino-encino y una porción de bosque mesófilo de montaña (Jardín Haravéri, 2020). Como se sabe, a nivel nacional esta última comunidad vegetal alberga numerosas especies en riesgo; por lo que ese lugar, aunque ocupa una superficie muy reducida, podría alcanzar relevancia en la conservación de dicho ecosistema vulnerable. Con algunas recomendaciones, proyectos como este deberían ampliarse y fomentarse.

No obstante que este trabajo trata de mostrar la relevancia de SSO como un reservorio sobresaliente de especies endémicas y en riesgo, es claro que las estrategias adecuadas para la conservación de biodiversidad van más allá de los límites municipales o estatales. Sin embargo, estos pueden servir como referencia geográfica e incidir en la toma de decisiones gubernamentales. En varios trabajos se ha reconocido que las cadenas montañosas del occidente de Jalisco donde confluyen la Sierra Madre del Sur, el Eje Volcánico Transmexicano y la Costa Pacífica Mexicana -entre los municipios Talpa de Allende, Mascota, Cabo Corrientes y San Sebastián del Oeste-, concentran una alta diversidad de especies y endemismo florístico. Esa información se rescata de contribuciones al conocimiento de la tribu Heliantheae (Villaseñor, 1991), los géneros Cosmos (Vargas-Amado et al., 2013, 2019), Quercus (González-ViIlarreal, 2003, 2018), Salvia (González-Gallegos et al., 2013, 2016) y Pinus (Pérez de la Rosa, 2009; Pérez de la Rosa y Gernandt, 2017), y de varias familias (Hernández-López, 1995). Además, en esta área se encuentran ecosistemas relictuales tales como un bosque de maple (Vázquez et al., 2000b), múltiples parches de bosque mesófilo de montaña (Reynoso-Dueñas, 2004; Cuevas et al., 2010) y bosque de Abies (Guerrero-Hernández et al., 2014). Por lo anterior, el occidente de Jalisco adquiere alta prioridad para la conservación.

En el caso de los hongos, ya se ha mencionado que los trabajos sobre diversidad a escala mundial estos han sido poco o nada tomados en cuenta; razón por la cual, su estudio debería ser un elemento para considerarse en los programas sobre biodiversidad, conservación y uso (Guzmán, 1995). Lo anterior debido a que los hongos son organismos que pueden afectar el ecosistema donde crecen, ya que generan una protección importante a la biodiversidad nativa en forma directa o indirecta (Heilmann-Clausen y Christensen, 2003). Esto último hace referencia en parte a las micorrizas, relación simbiótica entre planta-hongo generalmente presente en bosques templados y tropicales, $y$ que en ocasiones se da en forma muy específica o estricta. 
Por lo tanto, las amenazas a aquellas plantas de las que dependen los hongos, o viceversa, podrían detonar efectos en cascada que vulneren la calidad y dinámica propia del ecosistema. Asimismo, la destrucción de los diferentes tipos de vegetación del país repercute considerablemente sobre las poblaciones de las especies fúngicas, lo que podría ocasionar la pérdida o extinción de muchas de ellas, incluso antes de ser estudiadas o catalogadas en muchas de las comunidades vegetales, como es el caso de las zonas tropicales del occidente del país.

De los pocos trabajos que se tienen en México sobre especies de hongos considerados como raros, amenazados o en riesgo de extinción y su posible conservación, está el de Vovides et al. (1997). En este se presenta el número de especies registradas en algunas de las categorías de la UICN. En el caso del reino Fungi, se incluyen las amenazadas por la comercialización de sus esporomas, las raras y, por último, las que están en peligro de extinción debido a la destrucción de su hábitat.

En lo referente a los hongos catalogados de SSO por Rodríguez et al. (2019), se encontró que la mayoría se distribuyen principalmente en los bosques de pino-encino y mesófilo de montaña; caso parecido a lo señalado por Mueller y Halling (1995), quienes observaron esto a una escala mayor en bosques neotropicales de América.

Las 17 especies fúngicas propuestas para ser consideradas en alguna categoría de riesgo (Cuadro 6), son propuestas debido a su restringida distribución y hábitat. Lo anterior se basa en que dichos taxones se tienen registrados para el occidente de México solo del municipio de SSO. Cabe destacar, de acuerdo al listado de Rodríguez et al. (2019), a Psilocybe laurae Guzmán y Psilocybe villarrealiae Guzmán como especies microendémicas, ya que hasta ahora solo se han encontrado en sus respectivas localidades tipo. Pluteus horakianus Rodr.-Alcánt colectada en SSO, sitio en que se describió por primera vez, se considera endémica para el occidente, al encontrarse también en los estados de Colima y Nayarit. La mayoría de las especies antes mencionadas crecen en bosque mesófilo de montaña, tipo de vegetación en el cual se registra también un alto grado de endemismo en plantas. Esta situación coincide con lo citado por Vovides et al. (1997) en donde el mayor número de especies de hongos en riesgo se encuentran en bosque mesófilo de montaña, seguido por el de coníferas y encinares (Fig. 6).

Cuadro 6: Taxones de hongos propuestos para ser considerados en alguna categoría de riesgo por su restringida distribución en el occidente de México. * Especie microendémica restringida en su distribución al municipio San Sebastián del Oeste (SSO), Jalisco, México.

\begin{tabular}{l} 
Taxones \\
\hline Coltricia pseudocinnamomea Burds. \\
Entonaema cinnabarinum (Cooke \& Massee) Lloyd \\
Entonaema moluccanum J.D. Rogers \\
Hymenopellis radicata (Relhan) R.H. Petersen \\
Lacrymaria lacrymabunda (Bull.) Pat. \\
Leccinum cyaneobasileucum Lannoy \& Estadès \\
Microporellus dealbatus (Berk. \& M.A. Curtis) Murrill \\
Neoalbatrellus caeruleoporus (Peck) Audet \\
Pluteus salicinus (Pers.) P. Kumm. \\
* Psilocybe laurae Guzmán \\
* Psilocybe villarrealiae Guzmán \\
Scutiger pes-caprae (Pers.) Bondartsev \& Singer \\
Sebacina confusa R. Kirschner \& Oberw. \\
Thelephora arbuscula Corner \\
Trogia buccinalis (Mont.) Pat. \\
Veloporphyrellus pantoleucus L.D. Gómez \& Singer \\
Xerula setulosa (Murrill) R.H. Petersen \& T.J. Baroni \\
\hline
\end{tabular}



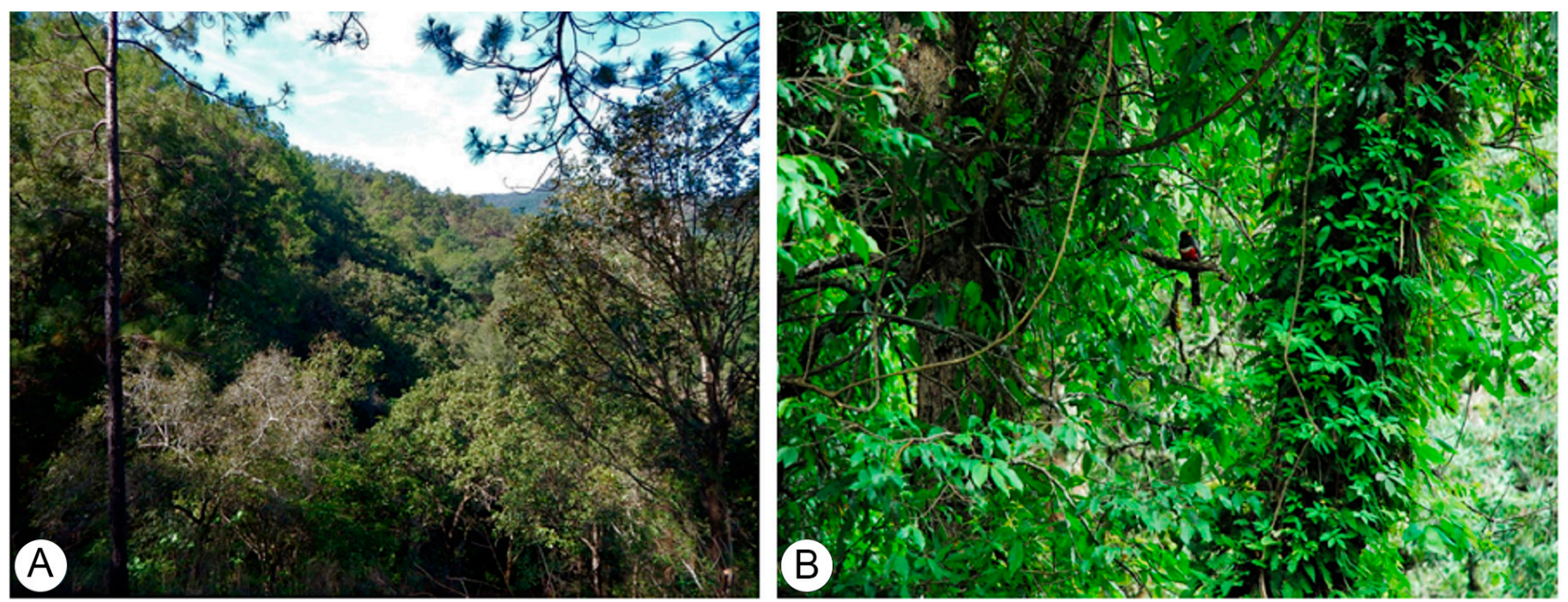

Figura 6: A. bosque de pino-encino; B. bosque mesófilo de montaña, tipos de vegetación que albergan el mayor número de especies en riesgo y endémicas de plantas y hongos en San Sebastián del Oeste, Jalisco, México. Fotografías de L. Hernández López (A) y O. Rodríguez Alcántar (B).

Serán necesarias futuras investigaciones ecológicas y biogeográficas para delimitar áreas de endemismo en hongos y su posible relación con los distintos patrones de vegetación; de esta manera, se podrían asegurar los beneficios que estos generan y también conocer el nivel de deterioro ambiental con la finalidad de mitigarlo.

Por último, con base en los resultados de este trabajo, podemos señalar que San Sebastián del Oeste es una zona de gran importancia biológica y debe conservarse bajo criterios de sustentabilidad para el aprovechamiento y disfrute de generaciones futuras.

\section{Contribución de autores}

LHL desarrolló una base de datos preliminar de plantas; junto con ORA analizaron la información y escribieron el manuscrito de plantas y hongos, respectivamente. DFG participó en la revisión y edición de la bibliografía, cuadros y figuras, y colaboró en la actualización de la base de datos de plantas y hongos. JJRD apoyó en la compilación de información de plantas. AA elaboró los gráficos incluidos. Todos los autores contribuyeron en la revisión crítica del contenido y aprobación del manuscrito final.

\section{Financiamiento}

Se agradece al Centro Universitario de Ciencias Biológicas y Agropecuarias de la Universidad de Guadalajara, por el financiamiento a través de los proyectos P3E (2019246472 y 2020-251939) otorgados al Cuerpo Académico UDG-CA-48.

\section{Agradecimientos}

Los autores agradecen a Ana Luisa Santiago Pérez, por la revisión del manuscrito y a Mollie Harker, por la revisión del resumen en inglés. Se agradece a Guadalupe Munguía Lino, del Laboratorio Nacional de Identificación y Caracterización Vegetal (LANIVEG), Unidad Biogeográfica, por la elaboración del mapa y por determinar las regiones biogeográficas presentes en el área de estudio; así como a las personas que facilitaron material fotográfico de su autoría cuyo crédito se menciona en las figuras correspondientes. Extendemos nuestro agradecimiento a los revisores anónimos y al editor, por los comentarios y sugerencias para mejorar el manuscrito.

\section{Literatura citada}

Acosta-Castellanos, S. 2002. Plantas vasculares raras, amenazadas, o en peligro de extinción del estado de Oaxaca, un panorama preliminar. Polibotánica 13: 47-82.

Aguirre-Acosta, E., M. Ulloa, S. Aguilar, J. Cifuentes y R. Valenzuela. 2014. Biodiversidad de hongos en México. Revista Mexicana de Biodiversidad 85: S76-S81. DOI: https://doi.org/10.7550/ rmb.33649 
APG IV. 2016. An update of the Angiosperm Phylogeny Group classification for the orders and families of flowering plants: APG IV. Botanical Journal of the Linnean Society 181(1): 1-20. DOI: https://doi.org/10.1111/boj.12385

Aragón-Parada, J., P. Carrillo-Reyes, A. Rodríguez y G. MunguíaLino. 2019. Diversidad y distribución geográfica del género Sedum (Crassulaceae) en la Sierra Madre del Sur, México. Revista Mexicana de Biodiversidad 90: 1-17. DOI: https:// doi.org/10.22201/ib.20078706e.2019.90.2921

Arriaga, L., J. M. Espinoza, C. Aguilar, E. Martínez, L. Gómez y E. Loa. 2000. Regiones terrestres prioritarias de México. Comisión Nacional para el Conocimiento y Uso de la Biodiversidad (CONABIO). Cd. Mx., México. http://www.conabio.gob. $\mathrm{mx} /$ conocimiento/regionalizacion/doctos/terrestres.html (consultado marzo de 2020).

Bautista-Hernández, S., T. Herrera, E. Aguirre-Acosta y M. Esqueda. 2011. Contribution to the taxonomy of Bovista in Mexico. Mycotaxon 118: 27-46. DOI: https://doi. org/10.5248/118.27

Byng, J. W. 2015. The Gymnosperms Handbook: A practical guide to extant families and genera of the world. Plant Gateway. Hertford, UK. 36 pp.

Byng, J. W., E. Smets, R. Vugt, E. Bidault, C. Davidson, G. Kenicer, M. W. Chase y M. J. Christenhusz. 2018. The phylogeny of angiosperms poster. Global Flora Gateway 1: 4-35.

Christenhusz, M. J. M. y J. M. Byng. 2016. The number of known plants species in the world and its annual increase. Phytotaxa 261(3): 201-217. DOI: https://doi.org/10.11646/ phytotaxa.261.3.1

Cifuentes, J., M. Villegas, R. García-Sandoval, G. Vidal-Gaona, S. Sierra, R. Valenzuela-Garza, L. Pérez-Ramírez y E. Morales-Torres. 2004. Distribución de macromicetos: Una aproximación al análisis de áreas de endemismo. In: Luna, I., J. J. Morrone y D. Espinoza (eds.). Biogeografía de la Sierra Madre Oriental. Comisión Nacional para el Conocimiento y Uso de la Biodiversidad (CONABIO) y Universidad Nacional Autónoma de México (UNAM). Cd. Mx., México. Pp. 355374.

CITES. 2019. Convención sobre el Comercio Internacional de Especies Amenazadas de Fauna y Flora Silvestres. https:// cites.org/esp/disc/species.php (consultado enero de 2020).

CONABIO. 2004. Regiones terrestres prioritarias, escala 1:1000000. Comisión Nacional para el Conocimiento y Uso de la Biodiversidad. Cd. Mx., México. http://geoportal. conabio.gob.mx/descargas/mapas/imagen/96/rtp1mgw (consultado julio de 2020).

CONABIO. 2010. El Bosque Mesófilo de Montaña en México: Amenazas y Oportunidades para su Conservación y Manejo Sostenible. Comisión Nacional para el Conocimiento y Uso de la Biodiversidad (CONABIO). Cd. Mx., México. 197 pp.

CONABIO. 2020. Biodiversidad mexicana: Categorías de riesgo en México. Comisión Nacional para el Conocimiento y Uso de la Biodiversidad (CONABIO). Cd. Mx., México. https:// www.biodiversidad.gob.mx/especies/catRiesMexico.html (consultado mayo de 2020).

CONABIO, IB-UNAM, CONANP, PNUD, INECC. 2020. Reporte de áreas seleccionadas. Explorador de cambio climático y biodiversidad. Comisión Nacional para el Conocimiento y Uso de la Biodiversidad (CONABIO). Cd. Mx., México. https://www.biodiversidad.gob.mx/pais/cambio-climatico (consultado julio de 2020).

CONANP. 2020. Cuenca alimentadora del Distrito de Riego 043 estado de Nayarit, en lo respectivo a las subcuencas de los ríos Ameca, Atenguillo, Bolaños, Grande de Santiago, Juchipila, Atengo y Tlaltenango. Comisión Nacional de Áreas Naturales Protegidas (CONANP) https://simec.conanp.gob. $\mathrm{mx} /$ ficha_pdf.php?anp=4\&reg=11 (consultado enero de 2020).

Courtecuisse, R. 2001. Current trends and perspectives of the global conservation in fungi. In: Moore, D., M. M. Nauta., S. E. Evans y M. Rotheroe (eds.). Fungal Conservation. Cambridge University Press. Cambridge, UK. Pp. 7-18.

Cuevas, G. R., J. G. González G., L. Hernández-López, L. I. Iñiguez D., E. Jardel P., P. Rodríguez M. y A. L. Santiago P. 2010. Sierra Madre del Sur y Franja Neovolcánica. In: CONABIO. El bosque mesófilo de montaña en México: Amenazas y Oportunidades para su conservación y manejo sostenible. Comisión Nacional para el Conocimiento y Uso de la Biodiversidad (CONABIO). Cd. Mx., México. Pp. 68-79.

Dávila, P., M. T. Mejía-Saulés, A. M. Soriano-Martínez y Y. HerreraArrieta. 2018. Conocimiento taxonómico de la familia Poaceae en México. Botanical Sciences 96: 462-514. DOI: https://doi.org/10.17129/botsci.1894

Espejo-Serna, A. y A. R. López-Ferrari. 2018. La familia Bromeliaceae en México. Botanical Sciences 96: 533-554. DOI: https://doi.org/10.17129/botsci.1918 
Gándara-Zamorano, E., L. Guzmán-Dávalos, G. Guzmán y O. Rodríguez. 2014. Inventario micobiótico de la región de Tapalpa, Jalisco, México. Acta Botanica Mexicana 107: 165187. DOI: https://doi.org/10.21829/abm107.2014.207

GBIF. 2020. Global Biodiversity Information Facility. Copenhagen, Denmark. https://www.gbif.org/ (consultado enero de 2020).

González-Elizondo, M. S., A. A. Reznicek y J. A. Tena-Flores. 2018. Cyperaceae in Mexico: Diversity and distribution. Botanical Sciences 96: 305-331. DOI: https://doi.org/10.17129/ botsci. 1870

González-Espinosa, M., J. A. Meave, F. G. Lorea-Hernández, G. Ibarra-Manríquez y A. C. Newton. 2011. The red list of Mexican cloud forest trees. Flora \& Fauna International. Cambridge, UK. 149 pp.

González-Gallegos, J. G., J. A. Vázquez-García y M. de J. CházaroBasáñez. 2013. Salvia carreyesii, Salvia ibugana and Salvia ramirezii (Lamiaceae), three new species from Jalisco, Mexico. Revista Mexicana de Biodiversidad 84: 7-19. DOI: https://doi.org/10.7550/rmb.29131

González-Gallegos, J. G., A. Castro-Castro, V. Quintero-Fuentes, M. E. Mendoza-López y E. de Castro-Arce. 2016. Revisión taxonómica de Lamiaceae del occidente de México. Ibugana 7: 3-545.

Guerrero-Hernández, R., J. G. González-Gallegos y A. CastroCastro. 2014. Análisis florístico de un bosque de Abies y el bosque mesófilo de montaña adyacente en Juanacatlán, Mascota, Jalisco, México. Botanical Sciences 92: 541-562. DOI: https://doi.org/10.17129/botsci.119

González-Villarreal, L. M. 2003. Two new species of oak (Fagaceae, Quercus sect. Lobatae) from the Sierra Madre del Sur, Mexico. Brittonia 55: 49-60.

González-Villarreal, L. M. 2018. Dos nuevas especies de encinos (Quercus: Fagaceae), adicionales para la Flora de Jalisco y Áreas Colindantes, en el Occidente de México. Ibugana 9: 47-71.

Guzmán, G. 1995. La diversidad de hongos en México. Ciencias 39: 52-57.

Guzmán, G. 1998. Inventoring the fungi of Mexico. Biodiversity and Conservation 7: 369-384.

Guzmán, G., A. Cortes-Pérez, L. Guzmán-Dávalos, F. RamírezGuillén y M. R. Sánchez-Jácome. 2013. An emendation of Scleroderma, new records, and review of the known species in Mexico. Revista Mexicana de Biodiversidad 84: S173-S191. DOI: https://doi.org/10.7550/rmb.31979

Harker, M., L. Hernández-López, J. J. Reynoso-Dueñas, L. M. González-Villarreal, M. Cedano-Maldonado, J. A. AriasGarcía, L. Villaseñor-Ibarra y V. Quintero-Fuentes. 2017. Actualización de la flora vascular de San Sebastián del Oeste, Jalisco, México. Ibugana 8: 3-63.

Hawksworth, D. L. 1991. Fungal dimension of biodiversity: magnitude, significance, and conservation. Mycological Research 95(6): 641-655. DOI: https://doi.org/10.1016/ S0953-7562(09)80810-1

Hawksworth, D. L. y R. Lücking. 2017. Fungal diversity revisited: 2.2 to 3.8 million species. Microbiology Spectrum 5(4): FUNK0052-2016. DOI: https://doi.org/10.1128/microbiolspec. funk-0052-2016

He, M. Q., R. L. Zhao, K. D. Hyde, D. Begerow, M. Kemler, A. Yurkov, E. H. C. McKenzie, O. Raspé, M. Kakishima, S. Sánchez-Ramírez, E. C. Vellinga, R. Halling, V. Papp, I. V. Zmitrovich, B. Buyck, D. Ertz, N. N. Wijayawardene, B. K. Ciu, N. Schoutteten, X. Z. Liu, T. H. Li, Y. J. Yao, X. Y. Zhu, A. Q. Liu, G. J. Li, M. Z. Zhang, Z. L. Ling, B. Cao, V. Antonín, T. Boekhout, B. D. Barbosa da Silva, E. De Crop, C. Decock, B. Dima, A. Kumar Dutta, J. W. Fell, J. Geml, M. Ghobad-Nejhad, A. J. Giachini, T. B. Gilbertoni, S. P. Gorjón, D. Haelewaters, S. H. He, B. P. Hodkinson, E. Horak, T. Hoshino, A. Justo, Y. W. Lim, N. Menolli Jr., A. Mešić, J. M. Moncalvo, G. M. Mueller, L. G. Nagy, R. Henrik Nilsson, M. Noordeloos, J. Nuytinck, T. Orihara, C. Rattchadawan, M. Rajchenberg, A. G. S. Silva-Filho, M. Aloisio Sulzbacher, Z. Tkalčec, R. Valenzuela, A. Verbeken, A. Vizzini, F. Wartchow, T. Z. Wei, M. Wei, C. L. Zhao y P. M. Kirk. 2019. Notes, outline and divergence times of Basidiomycota. Fungal Diversity 99: 105-367

Heilmann-Clausen, J. y M. Christensen. 2003. Fungal diversity on decaying beech logs - implications for sustainable forestry. Biodiversity and Conservation 12: 953-973. DOI: https:// doi.org/10.1023/A:1022825809503

Hernández-López, L. 1995. The endemic flora of Jalisco, Mexico: Centers of endemism and implications for conservation. Tesis de maestría. Universidad de Wisconsin. Madison, USA. $74 \mathrm{pp}$. 
Hernández-López, L. 2019. Las especies endémicas de plantas en el estado de Jalisco: su distribución y conservación. Comisión Nacional para el Conocimiento y Uso de la Biodiversidad (CONABIO). Cd. Mx., México. https://doi. org/10.15468/ktvqds (consultado diciembre de 2019).

IBDATA. 2020. Colecciones Biológicas Nacionales. Instituto de Biología de la Universidad Nacional Autónoma de México (UNAM). Cd. Mx., México. http://www.ibdata.ib.unam.mx/ web/web-content/admin-registro/registro.php (consultado mayo de 2020).

INAFED. 2010. Enciclopedia de los Municipios y Delegaciones de México: Jalisco. Instituto Nacional para el Federalismo y el Desarrollo Municipal. http://www.inafed.gob.mx/ work/enciclopedia/EMM21puebla/index.html (consultado diciembre de 2018).

Index Fungorum. 2020. The global fungal nomenclator. http:// www.indexfungorum.org/names/Names.asp (consultado mayo de 2020)

INE. 1994. Norma Oficial Mexicana NOM-059-ECOL-1994, que determina las especies y subespecies de flora y fauna silvestres terrestres y acuáticas en peligro de extinción, amenazadas, raras y las sujetas a protección especial, y que establece especificaciones para su protección. Diario Oficial de la Federación. México, D.F. México..

IPBES. 2019. Intergovernmental Science-Policy Platform on Biodiversity and Ecosystem Services. UN Environment Programme. Bonn, Germany. https://ipbes.net/ (consultado diciembre de 2019).

Isaac, N. J. B. y G. Cowlishaw. 2004. How species respond to multiple extinction threats. Proceedings of the Royal Society B: Biological Sciences 271(1554): 1135-1141. DOI: https://doi.org/10.1098/rspb.2004.2724

Jardel-Peláez, E. J., E. Santana-C., S. H. Graf, L. HernándezLópez, C. Valencia, R. González Franco y M. Meiners. 2017. Conservación y Restauración. In: Comisión Nacional para el Conocimiento y Uso de la Biodiversidad y Secretaría de Medio Ambiente y Desarrollo Territorial (eds.). La Biodiversidad de Jalisco: Estudio de Estado volumen I. Comisión Nacional para el Conocimiento y Uso de la Biodiversidad (CONABIOSEMADET). Cd. Mx., México. Pp. 275-316.

Jardín Haravéri. 2020. Jardín botánico Haravéri. Proyecto Nebulosa. San Sebastián del Oeste, México. www. jardinharaveri.com (consultado junio de 2020).
Knight, A. T., R. M. Cowling, M. Rouget, A. Balmford, A. T. Lombard y B. M. Campbell. 2008. Knowing but not doing: selecting priority conservation areas and the researchimplementation gap. Conservation Biology 22: 610617. DOI: https://conbio.onlinelibrary.wiley.com/doi/ full/10.1111/j.1523-1739.2008.00914.x

Koleff, P., T. Urquiza-Haas, S. P. Ruiz-González, D. R. HernándezRobles, A. Mastretta-Yanes, E. Quintero y J. Sarukhán. 2019. Biodiversity in Mexico: State of Knowledge. In: Pullaiah, T. (ed.). Global Biodiversity, vol. 4: Selected Countries in the Americas and Australia. Apple Academic Press. Waretown, USA. 574 pp.

Landeros, F. y L. Guzmán-Dávalos. 2013. Revisión del género Helvella (Ascomycota: Fungi) en México. Revista Mexicana de Biodiversidad 84: S3-S20. DOI: https://doi.org/10.7550/ rmb.31608

Larsen, B. B., E. C. Miller, M. K. Rhodes y J. J. Wiens. 2017. Inordinate fondness multiplied and redistributed: the number of species on Earth and the new pie of life. Quarterly Review of Biology 92(3): 229-2265. https://doi. org/10.1086/693564

Llorente-Bousquets, J. y S. Ocegueda. 2008. Estado del conocimiento de la biota. In: Soberón, J., G. Halffter y J. Llorente (eds.). Capital Natural de México, vol. 1: Conocimiento actual de la Biodiversidad. Comisión Nacional para el Conocimiento y Uso de la Biodiversidad (CONABIO). Cd. Mx., México. Pp. 283-322.

López-Ramírez, A. y R. Medel. 2016. Hongos (Fungi). In: Cruz Angón, A., M. A. Ortega Huerta, E. D. Melgarejo, H. Perdomo Velázquez y A. V. Contreras (eds.). La Biodiversidad en Colima. Estudio de Estado. Comisión Nacional para el Conocimiento y Uso de la Biodiversidad (CONABIO). Cd. Mx., México. Pp. 177-181.

Martínez, M., O. Vargas-Ponce, A. Rodríguez, F. Chiang y S. Ocegueda. 2017. Solanaceae family in Mexico. Botanical Sciences 95(1): 131-145. DOI: https://doi.org/10.17129/ botsci.658

Martínez-Camilo, R., M. A. Pérez-Farrera y N. Martínez-Meléndez. 2012. Listado de plantas endémicas y en riesgo de la reserva de la biosfera El Triunfo, Chiapas, México. Botanical Sciences 90(3): 263-285. DOI: https://doi.org/10.17129/botsci.390 Martínez-Gordillo, M. J., B. Bedolla-García, G. Cornejo-Tenorio, I. Fragoso-Martínez, M. R. García-Peña, J. G. González- 
Gallegos, S. Lara-Cabrera y S. Zamudio. 2017. Lamiaceae de México. Botanical Sciences 95(4): 780-806. DOI: https://doi. org/10.17129/botsci.1871

MEA. 2005. Ecosystems and Human Well-being: Opportunities and Challenges for Business and Industry. Millennium Ecosystem Assessment (MEA), World Resources Institute. Washington, USA. $36 \mathrm{pp}$.

Montañez, D., M. E. Noordeloos, O. Rodríguez, O. Vargas y L. Guzmán-Dávalos. 2016. Notes on the genus Entoloma (Basidiomycota, Agaricales) in two volcanic areas of Jalisco, Mexico. Phytotaxa 277: 211-236. DOI: https://doi. org/10.11646/phytotaxa.277.3.1

Morrone, J. J., T. Escalante y G. Rodríguez-Tapia. 2017. Mexican biogeographic provinces: map and shapefiles. Zootaxa 4277(2): 277-279 DOI: https://doi.org/10.11646/ zootaxa.4277.2.8

Mueller, G. M. y R. E. Halling. 1995. Evidence for High Biodiversity of Agaricales (Fungi) in Neotropical Montane Quercus Forest. In: Churchill, S. P., H. Balsev, E. Forero y J. L. Luteyn (eds.). Biodiversity and Conservation of Neotropical Montane Forests. The New York Botanical Garden. Nueva York, USA. Pp. 303-312.

Mueller, G. M., J. P. Schmit, P. R. Leacock, B. Buyck, J. Cifuentes, D. E. Desjardin, R. E. Halling, K. Hjotstam, T. Iturriaga, K. H. Larsson, D. J. Lodge, T. W. May, D. Minter, M. Rajchenberg, S. A. Redhead, L. Ryvarden, J. M. Trappe, R. Watling y Q. Wu. 2007. Global diversity and distribution of macrofungi. Biodiversity and Conservation 16: 37-48. DOI: https://doi. org/10.1007/s10531-006-9108-8

Munguía-Lino, G., A. Castro-Castro y A. Rodríguez. 2018. Nuevos registros de ocho especies de Tigridieae (Iridaceae) en México. Ibugana 9: 21-46.

MycoBank. 2020. Fungal Databases, Nomenclature and species banks. http://www.mycobank.org/quicksearch.aspx (consultado mayo de 2020).

Padilla-Velarde, E. E., G. Zarco-Velazco, L. Guzmán-Dávalos y R. Cuevas-Guzmán. 2016. Primera contribución al conocimiento de Macromicetos de la vertiente norte del cerro El Cípil, en la costa sur de Jalisco. Acta Botanica Mexicana 114: 137-167. DOI: https://doi.org/10.21829/ abm114.2016.1105
Pérez de la Rosa, J. A. 2009. Pinus georginae (Pinaceae), a new species from western Jalisco, Mexico. Brittonia 61: 56-61. DOI: https://doi.org/10.1007/s12228-008-9061-9

Pérez de la Rosa, J. A. y D. S. Gernandt. 2017. Pinus vallartensis (Pinaceae), a new species from western Jalisco, Mexico. Phytotaxa 331(2): 233-242. DOI: https://doi.org/10.11646/ phytotaxa.331.2.7

PPG I. 2016. A community-derived classification for extant lycophytes and ferns. Journal of Systematics and Evolution 54(6): 563-603. DOI: https://doi.org/10.1111/jse.12229

Pulido-Pérez, S. I. 2008. Contribución al estudio de los macromicetos de la Estación de Biología Chamela, Jalisco, México. Universidad Nacional Autónoma de México (UNAM). Cd. Mx., México. 61 pp.

Ramírez-Delgadillo, R. y J. J. Reynoso-Dueñas. 2000. Flora y vegetación. In: Vázquez-García J. A., J. J. Reynoso-Dueñas, Y. L. Vargas-Rodríguez y H. Frias (eds.). Jalisco-Costa Norte: Patrimonio ecológico. Cultural y productivo de México. Instituto de Botánica, Centro Universitario de Ciencias Biológicas y Agropecuarias, Universidad de Guadalajara. Guadalajara, México. Pp. 166-184.

Ramírez-Delgadillo, R., O. Vargas-Ponce, H. J. Arreola-Nava, M. Cedano-Maldonado, R. González-Tamayo, L. M. GonzálezVillarreal, M. Harker, L. Hernández-López, R. E. MartínezGonzález, J. A. Pérez de la Rosa, A. Rodríguez-Contreras, J. J. Reynoso-Dueñas, L. M. Villarreal de Puga y J. L. VillaseñorRíos. 2010. Catálogo de plantas vasculares de Jalisco. Prometeo Editores S.A. de C.V. Guadalajara, México. 143 pp. Raymundo, T., R. Valenzuela, S. Bautista-Hernández, M. Esqueda, J. Cifuentes y L. Pacheco. 2013. El género Fuscoporia (Hymenochaetales, Basidiomycota) en México. Revista Mexicana de Biodiversidad 84: S50-S69. DOI: https://doi. org/10.7550/rmb.31604

REMIB. 2020. Red mundial de información sobre biodiversidad. Comisión Nacional para el Conocimiento y Uso de la Biodiversidad (CONABIO). Cd. Mx., México. http:// www.conabio.gob.mx/remib/doctos/remib_esp.html (consultado enero de 2020).

Reynoso-Dueñas, J. J. 2004. Florística y fitogeografía de la flora arbórea del bosque mesófilo de montaña en San Sebastián del Oeste, Jalisco, México. Tesis de maestría. Universidad de 
Guadalajara. Guadalajara, México. 97 pp.

Reynoso-Dueñas, J. J., L. Hernández López, R. Ramírez-Delgadillo, M. Harker, M. Cedano e I. Álvarez. 2006. Catálogo preliminar de la flora vascular y micobiota del municipio de San Sebastián del Oeste, Jalisco, México. Ibugana 14: 51-91.

Ricketts, T. H., E. Dinerstein, T. Boucher, T. M. Brooks, S. H. M. Butchart, M. Hoffmann, Lamoreux, J. Morrison, M. Parr, J. D. Pilgrim, A. S. L. Rodrigues, W. Sechrest, G. E. Wallace, K. Berlin, J. Bielby, N. D. Burgess, D. R. Church, N. Cox, D. Knox, C. Loucks, G. W. Luck, L. L. Master, R. Moore, R. Naidoo, R. Ridgely, G. E. Schatz, G. Shire, H. Strand, W. Wettengel y E. Wikramanayake. 2005. Pinpointing and preventing imminent extinctions. Proceedings of the National Academy of Sciences 102(51): 18497-18501. DOI: https:// doi.org/10.1073/pnas.0509060102

Rodríguez, O. 2013. El género Pluteus (Agaricales, Pluteaceae) en México. Revista Mexicana de Biodiversidad 84: 128-151. DOI: https://doi.org/10.7550/rmb.31610

Rodríguez, O., A. Galván-Corona, A. R. Villalobos-Arámbula, G. Vargas y L. Guzmán-Dávalos. 2009. Pluteus horakianus, a new species from Mexico, based on morphological and molecular data. Sydowia 61: 39-52.

Rodríguez, O., A. Galván-Corona, A. R. Villalobos-Arámbula, A. Rodríguez y L. Guzmán-Dávalos. 2010a. A new species of Pluteus (Pluteaceae, Agaricales) from Mexico. Mycotaxon 112: 163-172. DOI: https://doi.org/10.5248/112.163

Rodríguez, O., M. Herrera-Fonseca, M. R. Sánchez-Jácome, I. Álvarez, R. Valenzuela, J. García y L. Guzmán-Dávalos. 2010b. Catálogo de la Micobiota del bosque La Primavera, Jalisco. Revista Mexicana de Micología 32: 29-40.

Rodríguez, O., M. Herrera-Fonseca y A. Galván-Corona. 2013. Nuevos registros de Basidiomycota para Jalisco, México. Acta Botanica Mexicana 105: 45-58. DOI: https://doi. org/10.21829/abm105.2013.226

Rodríguez, O., D. Figueroa-García y M. J. Herrera-Fonseca. 2018. Catálogo de los hongos del Volcán de Tequila, municipio de Tequila, Jalisco, México. Polibotánica 45: 15-33. DOI: https://doi.org/10.18387/polibotanica.45.3

Rodríguez, O., D. Figueroa-García y M. J. Herrera-Fonseca. 2019. Catálogo de los hongos de San Sebastián del Oeste, municipio de San Sebastián del Oeste, Jalisco, México. Acta Botanica Mexicana 126: e1364. DOI: https://doi. org/10.21829/abm126.2019.1364
Rodríguez, O., L. Hernández López, J. J. Reynoso Dueñas y D. Figueroa-García. 2020. Los hongos en Sierra de Quila, Jalisco, registros nuevos. e-CUCBA 13: 1-4.

Rzedowski, J. 1978. Vegetación de México. Ed. Limusa. México, D.F., México. 432 pp.

Rzedowski, J. 1996. Análisis preliminar de la flora vascular de los bosques mesófilos de montaña de México. Acta Botanica Mexicana 35: 25-44. DOI: https://doi.org/10.21829/ abm35.1996.955

Rzedowski, J. 2020. Catálogo preliminar de especies de plantas vasculares de distribución restringida al eje volcánico transversal. Flora del Bajío y de Regiones Adyacentes, fascículo complementario 34: 1-48.

Sánchez-Chávez, E. y S. Zamudio. 2019. Eugenia harkerae (Myrtaceae), a new species from Jalisco, Mexico. Brittonia 71: 394-397 DOI: https://doi.org/10.1007/s12228-01909595-8

Sánchez-Jácome, M. R. y L. Guzmán-Dávalos. 2011. Hongos citados para Jalisco, II. Ibugana 16: 25-60.

Sánchez-Ken, J. G. 2019. Riqueza de especies, clasificación y listado de las gramíneas (Poaceae) de México. Acta Botanica Mexicana 126: e1379. DOI: https://doi.org/10.21829/ abm126.2019.1379

Sarukhán, J., P. Koleff, J. Carabias, J. Soberón, R. Dirzo, J. LlorenteBousquets, G. Halffter, R. González, I. March, A. Mohar, S. Anta, J. de la Maza, I. Pisanty, T. Urquiza Haas, S. P. Ruiz González y G. García Méndez. 2017. Capital natural de México. Síntesis: evaluación del conocimiento y tendencias de cambio, perspectivas de sustentabilidad, capacidades humanas e institucionales. Comisión Nacional para el Conocimiento y Uso de la Biodiversidad (CONABIO). Cd. Mx., México. 126 pp.

SEMARNAT. 2002. NORMA Oficial Mexicana NOM-059-ECOL-2001, Protección ambiental-Especies nativas de México de flora y fauna silvestres-Categorías de riesgo y especificaciones para su inclusión, exclusión o cambio-Lista de especies en riesgo. Secretaría del Medio Ambiente y Recursos Naturales. Diario Oficial de la Federación. Cd. Mx., México. https://dof.gob. $\mathrm{mx} /$ nota_detalle.php?codigo=735036\&fecha=06/03/2002

SEMARNAT. 2010. Norma Oficial Mexicana NOM-059SEMARNAT-2020. Protección ambiental-Especies nativas de México de flora y fauna silvestres-Categorías de riesgo y especificaciones para su inclusión, exclusión o cambio, 
lista de especies en riesgo. Secretaría del Medio Ambiente y Recursos Naturales. Diario Oficial de la Federación. Cd. Mx., México. http://dof.gob.mx/nota_detalle. php?codigo $=5173091 \&$ fecha $=30 / 12 / 2010$

SEMARNAT. 2019. MODIFICACIÓN del Anexo Normativo III, Lista de especies en riesgo de la Norma Oficial Mexicana NOM-059-SEMARNAT-2010, Protección ambiental-Especies nativas de México de flora y fauna silvestres-Categorías de riesgo y especificaciones para su inclusión, exclusión o cambio-Lista de especies en riesgo, publicada el 30 de diciembre de 2010. Cd. Mx., México. http://www.dof.gob. mx/nota_detalle.php?codigo=5578808\&fecha=14/11/2019

Terríquez-Villanueva, A. K., M. J. Herrera-Fonseca y O. Rodríguez Alcántar. 2017. Contribución al conocimiento de la micobiota del cerro Punta Grande, Mezcala, municipio de Poncitlán, Jalisco, México. Scientia Fungorum 45: 53-66. DOI: https://doi.org/10.33885/sf.2017.0.1167

Torres-Colín, R., J. G. Parra, L. A. de la Cruz, M. P. Ramírez, C. Gómez-Hinostrosa, R. T. Bárcenas y H. M. Hernández. 2017. Flora vascular del municipio de Guadalcázar y zonas adyacentes, San Luis Potosí, México. Revista Mexicana de Biodiversidad 88: 524-554. DOI: https://doi.org/10.1016/j. rmb.2017.07.003

UICN. 2020. Categorías y Criterios de la Lista Roja de la UICN: Versión 2020-2. Cambridge, UK. https://www.iucnredlist. org/search?taxonomies $=100002 \&$ searchType=species (consultado marzo de 2020).

Uitzil-Colli, M. O. y L. Guzmán-Dávalos. 2019. El género Morchella (Pezizales, Ascomycota) en Jalisco, México. Scientia Fungorum 49: 1-8. DOI: https://doi.org/10.33885/ sf.2019.49.1209

Vargas-Amado, G., A. Castro-Castro, M. Harker, J. L. Villaseñor, E. Ortiz y A. Rodríguez. 2013. Distribución geográfica y riqueza del género Cosmos (Asteraceae: Coreopsideae). Revista Mexicana de Biodiversidad 84: 536-555. DOI: https://doi. org/10.7550/rmb.31481

Vargas-Amado, G., A. Castro-Castro, M. Harker, M. E. VargasAmado, J. L. Villaseñor, E. Ortiz y A. Rodríguez. 2019. Western Mexico is a priority area for the conservation of Cosmos (Coreopsideae, Asteraceae), based on richness and track analysis. Biodiversity and Conservation 29(2): 545-569. DOI: https://doi.org/10.1007/s10531-01901898-2
Vázquez, G. J. A., J. J. Reynoso Dueñas, R. Y. L. Vargas y U. H. G. Frías U.H.G. 2000a. Jalisco Costa-Norte: Patrimonio Ecológico, Cultural y Productivo de México. Instituto de Botánica, Centro Universitario de Ciencias Biológicas y Agropecuarias, Universidad de Guadalajara. Guadalajara, México. 315 pp.

Vázquez, G. J. A., Y. Vargas y F. Aragón C. 2000b. Descubrimiento de un bosque de Acer-Podocarpus-Abies en el municipio de Talpa de Allende, Jalisco, México. Boletín del Instituto de Botánica de la Universidad de Guadalajara 7(1-3): 159-183.

Vázquez, G. J. A., V. Shalisko, R. Cuevas-Guzmán, M. A. MuñizCastro y M. R. Mantilla-Blandón. 2014. Abies jaliscana (Pinaceae): A new combination in section Grandis and a kew to the species of Abies in western Mexico. Phytotaxa 183(1): 027-036. DOI: https://doi.org/10.11646/phytotaxa.183.1.3 Vega-Aviña, R., H. Aguilar-Hernández, J. A. Gutiérrez-García, J. A. Hernández-Vizcarra, I. F. Vega-López y J. L. Villaseñor. 2000. Endemismo regional presente en la flora del municipio de Culiacán, Sinaloa, México. Acta Botanica Mexicana 53: 1-15. DOI: https://doi.org/10.21829/abm53.2000.858

Villaseñor, J. L. 1991. Las Heliantheae endémicas a México: una guía hacia la conservación. Acta Botanica Mexicana 15: 2946. DOI: https://doi.org/10.21829/abm15.1991.619

Villaseñor, J. L. 2010. El bosque húmedo de montaña en México y sus plantas vasculares: catálogo florístico-taxonómico. Comisión Nacional para el Conocimiento y Uso de la Biodiversidad (CONABIO) y Universidad Nacional Autónoma de México (UNAM). Cd. Mx., México. 40 pp.

Villaseñor, J. L. 2016. Checklist of the native vascular plants of Mexico. Revista Mexicana de Biodiversidad 87(3): 559-902. DOI: https://doi.org/10.1016/j.rmb.2016.06.017

Villaseñor, J. L. 2018. Diversidad y distribución de la familia Asteraceae en México. Botanical Sciences 96: 332-358. https://doi.org/10.17129/botsci.1872

Vovides, A. P., V. Luna y G. Medina. 1997. Relación de algunas plantas y hongos mexicanos raros, amenazados o en peligro de extinción y sugerencias para su conservación. Acta Botanica Mexicana 39: 1-42. DOI: https://doi.org/10.21829/ abm39.1997.774

Whitten, T., D. Holmes y K. MacKinnon. 2001. Conservation biology: a displacement behavior for academia? Conservation Biology 15: 1-3.

Wijayawardene, N. N., K. D. Hyde, H. T. Lumbsch, J. Kuin-Liu, S. S. N. Maharachchikumbura, A. H. Ekanayaka, Q. Tian y R. 
Phookamsak. 2018. Outline of Ascomycota: 2017. Fungal Diversity 88: 167-263. DOI: https://doi.org/10.1007/ s13225-018-0394-8

Wilson, E. O. 1988. Biodiversity. National Academy of Sciences. Washington, USA. 538 pp.
Wilson, E. O. 1998. Consilience: the unity of knowledge. Vintage Books. New York. 367 pp. 


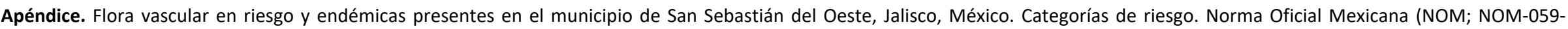

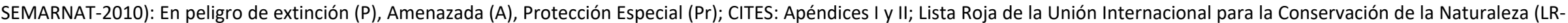

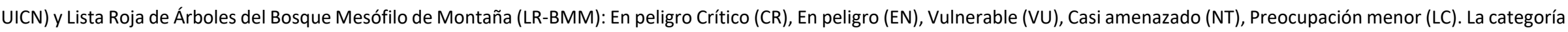

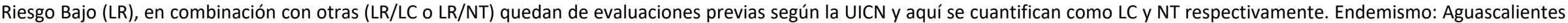

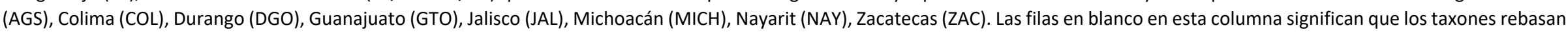

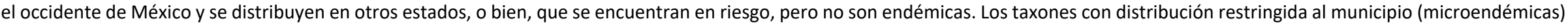

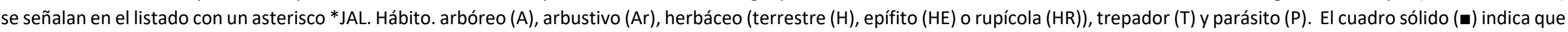

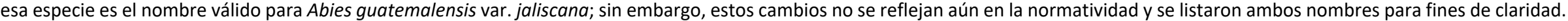

\begin{tabular}{|c|c|c|c|c|c|c|c|}
\hline \multirow[t]{2}{*}{ Grupo/Familia } & \multirow[t]{2}{*}{ Taxones } & \multirow[t]{2}{*}{ Hábito } & \multicolumn{4}{|c|}{ Categorías de riesgo } & \multirow[t]{2}{*}{ Endemismo } \\
\hline & & & NOM-059 & CITES & LR-UICN & LR-BMM & \\
\hline
\end{tabular}

\section{HELECHOS}

Polypodiidae

Aspleniaceae

Cyatheaceae

Osmundaceae

Asplenium formosum Willd.

$\mathrm{HR}$

LC

Cyathea costaricensis (Mett. ex Kuhn) Domin.

A

Osmunda regalis L. var. spectabilis (Willd.) A.

$\mathrm{H}$

P

II

Gray

Polypodiaceae

Campyloneurum phyllitidis (L.) C. Presl

HE, H

Adiantum capillus-veneris L.

$\mathrm{H}$

A

Pteridaceae

Anogramma novogaliciana Mickel

$\mathrm{H}$

$\mathrm{JAL}, \mathrm{MICH}$

\section{GIMNOSPERMAS}

\section{Cycadidae}

Zamiaceae

Pinidae

Cupressaceae

Dioon tomasellii De Luca, Sabato \& Vázq. Torres

Zamia loddigesii Miq.

$\mathrm{Ar}$

$\mathrm{Ar}$

Cupressus lusitanica Mill. subsp. benthamii

(Endl.) Franco

Juniperus flaccida Schltdl.

Pinaceae
Abies guatemalensis Rehder var. jaliscana

Martínez

-Abies jaliscana (Martínez) Mantilla, Shalisko \&

A. Vázquez

Pinus devoniana Lindl.

Pinus douglasiana Martínez

Pinus jaliscana Pérez de la Rosa

(20)

$\mathrm{Ar}$

A

A

A

A

A

A

A

A
$P$

A

$\operatorname{Pr}$

NT

LC

NT

VU

I

NT


Apéndice. Continuación

\begin{tabular}{|c|c|c|c|c|c|c|c|}
\hline \multirow[t]{2}{*}{ Grupo/Familia } & \multirow[t]{2}{*}{ Taxones } & \multirow[t]{2}{*}{ Hábito } & \multicolumn{4}{|c|}{ Categorías de riesgo } & \multirow[t]{2}{*}{ Endemismo } \\
\hline & & & NOM-059 & CITES & LR-UICN & LR-BMM & \\
\hline & Pinus lumholtzii B.L. Rob. \& Fernald & $A$ & & & NT & & \\
\hline & Pinus maximinoi H.E. Moore & $A$ & & & LC & LC & \\
\hline & Pinus oocarpa Schiede ex Schltdl. & $A$ & & & LC & & \\
\hline & Pinus pseudostrobus Lindl. & $A$ & & & LC & LC & \\
\hline & $\begin{array}{l}\text { Pinus vallartensis Pérez de la Rosa \& D. Ger- } \\
\text { nandt }\end{array}$ & $A$ & & & & & $J A L$ \\
\hline Podocarpaceae & Podocarpus matudae Lundell & $A$ & $\operatorname{Pr}$ & & VU & EN & \\
\hline
\end{tabular}

\section{ANGIOSPERMAS}

\section{Magnólidas}

Annonaceae

\section{Cymbopetalum hintonii Lundell}

Desmopsis mexicana R.E. Fr.

JAL, MICH,

NAY

Desmopsis trunciflora (Schltdl. \& Cham.) G.E.

A

JAL, MICH

Schatz

Aristolochiaceae

Aristolochia carterae Pfeifer

$\mathrm{T}$

Aristolochia pacifica Santana Mich. \& Paizanni T

JAL, NAY

Aristolochia rzedowskiana Santana Mich. \&

Guzm.-Hern.

COL, JAL

JAL

Chloranthaceae

Hedyosmum mexicanum C. Cordem.

Beilschmiedia manantlanensis Cuevas \& Cochrane

LC

Cinnamomum pachypodum (Nees) Kosterm.

EN

COL, NAY

Persea hintonii C.K. Allen

NT

Magnolia pacifica A.Vázquez

Piper hispidum Sw.

EN

Magnoliaceae

Piper pseudofuligineum C. DC.

A

Piperaceae

Thalictrum pringlei S. Watson

Ranunculaceae

Siparuna thecaphora (Poepp. \& Endl.) A. DC.

$\mathrm{H}$

Siparunaceae

Siparuna thecaphora (Poepp. \& Endl.) A. DC.

Ar

LC

LC

\section{Monocotiledóneas}

$\mathrm{COL}, \mathrm{JAL}$, $\mathrm{MICH}, \mathrm{NAY}$, ZAC 
Grupo/Familia

Taxones
Hábito

NOM-059

Cate
Endemismo

\section{Asparagaceae}

Bromeliaceae

Commelinaceae

Iridaceae

Melanthiaceae

Orchidaceae
Agave inaequidens K. Koch

Agave maximiliana Baker

Pitcairnia compostelae McVaugh

Commelina diffusa Burm. f.

Tigridia pugana Aarón Rodr. \& Ortiz-Catedral

Tigridia suarezii Aarón Rodr. \& Ortiz-Catedral

Schoenocaulon jaliscense var. regulare (Brinker)

Frame

Barkeria barkeriola Rchb. f.

Barkeria obovata (C. Presl) Christenson

Barkeria palmeri (Rolfe) Schltr.

Beloglottis costaricensis (Rchb. f.) Schltr.

Bletia ensifolia L.O. Williams

Bletia macristhmochila Greenm.

Bletia purpurata A. Rich. \& Galeotti

Brassavola cucullata (L.) R. Br.

Campylocentrum micranthum (Lindl.) Maury

Catasetum pendulum Dodson

Clowesia dodsoniana E. Aguirre

Cranichis apiculata Lindl.

Cranichis subumbellata A. Rich. \& Galeotti

Cypripedium irapeanum Lex.

Encyclia adenocaula (Lex.) Schltr.

Encyclia aenicta Dressler \& G.E. Pollard

Encyclia suaveolens Dressler

Epidendrum ciliare L.

Epidendrum marmoratum A. Rich. \& Galeotti

Epidendrum miserum Lindl.

Erycina echinata (Kunth) Lindl.
Ar

Ar

$\mathrm{H}$

$\mathrm{H}$

$\mathrm{H}$

$\mathrm{H}$

$\mathrm{H}$

HE

HE

HE

$\mathrm{H}$

$\mathrm{H}$

$\mathrm{H}$

H

HE

HE

HE

HE

$\mathrm{H}$

$\mathrm{H}$

$\mathrm{H}$

HE

HE

HE

HE

HE

HE

HE
LC

LC

JAL, NAY

LC

COL, JAL

COL, JAL
Pr

LC

VU 


\begin{tabular}{|c|c|c|c|c|c|c|c|}
\hline \multirow[t]{2}{*}{ Grupo/Familia } & \multirow[t]{2}{*}{ Taxones } & \multirow[t]{2}{*}{ Hábito } & \multicolumn{4}{|c|}{ Categorías de riesgo } & \multirow[t]{2}{*}{ Endemismo } \\
\hline & & & NOM-059 & CITES & LR-UICN & LR-BMM & \\
\hline & Galeoglossum tubulosum (Lindl.) Salazar & $\mathrm{H}$ & & II & & & \\
\hline & Govenia superba (La Llave \& Lex.) Lindl. & $\mathrm{H}$ & & II & & & \\
\hline & Guarianthe aurantiaca (Bateman ex Lindl.) & $\mathrm{HE}$ & & II & & & \\
\hline & Dressler \& W.E. Higgins & & & & & & \\
\hline & Habenaria agapitae R. González \& Reynoso & $\mathrm{H}$ & & II & & & \\
\hline & Habenaria aguirrei R. González \& Cuev.-Fig. & $\mathrm{H}$ & & II & & & \\
\hline & Habenaria clypeata Lindl. & $\mathrm{H}$ & & II & & & \\
\hline & Habenaria diffusa A. Rich. \& Galeotti & $\mathrm{H}$ & & II & & & \\
\hline & Habenaria distans Griseb. & $\mathrm{H}$ & & II & & & \\
\hline & Habenaria flexuosa Lindl. & $\mathrm{H}$ & & II & & & \\
\hline & Habenaria jaliscana S. Watson & $\mathrm{H}$ & & II & & & \\
\hline & Habenaria lizbethae R. González \& Cuev.-Fig. & $\mathrm{H}$ & & II & & & \\
\hline & Habenaria luzmariana R. González & $\mathrm{H}$ & & II & & & \\
\hline & Habenaria quinqueseta (Michx.) Eaton & $\mathrm{H}$ & & II & & & \\
\hline & $\begin{array}{l}\text { Habenaria sebastianensis R. González \& Cuev.- } \\
\text { Fig. }\end{array}$ & $\mathrm{H}$ & & II & & & *JAL \\
\hline & Hagsatera rosilloi R. González & $\mathrm{HE}$ & & II & & & COL, JAL \\
\hline & Isochilus chiriquensis Schltr. & $\mathrm{H}$ & & II & & & \\
\hline & Jacquiniella leucomelana (Rchb. f.) Schltr. & $\mathrm{HE}$ & & II & & & \\
\hline & Laelia crawshayana Rchb. f. & $\mathrm{HE}$ & $P$ & II & & & JAL \\
\hline & Leochilus oncidioides Knowles \& Westc. & HE & & II & & & \\
\hline & Liparis cordiformis C. Schweinf. & $\mathrm{H}$ & & II & & & \\
\hline & Malaxis chiarae R. González, Lizb. Hern. \& E. & $\mathrm{H}$ & & II & & & $\mathrm{COL}, \mathrm{JAL}$ \\
\hline & Ramírez & & & & & & \\
\hline & Malaxis fastigiata (Rchb. f.) Kuntze & $\mathrm{H}$ & & II & & & \\
\hline & Malaxis rosilloi R. González \& E.W. Greenw. & $\mathrm{H}$ & & II & & & \\
\hline & Maxillaria variabilis Bateman ex Lindl. & $\mathrm{HE}$ & & II & & & \\
\hline & Meiracyllium trinasutum Rchb. f. & $\mathrm{HE}$ & & II & & & \\
\hline & Mormodes badia Rolfe ex Watson & $\mathrm{HE}$ & & II & & & \\
\hline & Mormodes pardalinata S. Rosillo & $\mathrm{HE}$ & & II & & & JAL, NAY \\
\hline
\end{tabular}


Notylia barkeri Lindl.

Oncidium brachyandrum Lindl.

Oncidium ensatum Lindl.

Oncidium tigrinum Lex.

Ornithocephalus biloborostratus Salazar \& R.

González

Ornithocephalus inflexus Lindl.

Prosthechea concolor (Lex.) W.E. Higgins

Prosthechea pastoris (Lex.) Espejo \& López-Ferr.

Prosthechea pterocarpa (Lindl.) W.E. Higgins

Rhynchostele cervantesii (Lex.) Soto Arenas \&

Salazar

Rhynchostele maculata (Lex.) Soto Arenas \& Salazar

Rodriguezia dressleriana R. González

Rossioglossum insleayi (Barker ex Lindl.) Garay \& G.C. Kenn

Sarcoglottis schaffneri (Rchb. f.) Ames

Scaphyglottis imbricata (Lindl.) Dressler

Stanhopea martiana Bateman

Stelis quadrifida (Lex.) Solano \& Soto Arenas

Trichocentrum andreanum (Cogn.) R. Jiménez \& Carnevali

Trichocentrum cebolleta (Jacq.) M.W. Chase \&

N.H. Williams

Trichosalpinx tamayoana Soto Arenas

Aegopogon cenchroides Humb. \& Bonpl. ex Willd. var. cenchroides

Aegopogon cenchroides var. breviglumis (Scribn.) Beetle

Eleusine indica (L.) Gaertn.

Lasiacis divaricata (L.) Hitchc.

Leptochloa panacea subsp. brachiata (Steud.) N. Snow
$\mathrm{HE}$

$\mathrm{HE}$ 


\begin{tabular}{|c|c|c|c|c|c|c|c|}
\hline \multirow{2}{*}{ Grupo/Familia } & \multirow{2}{*}{ Taxones } & \multirow{2}{*}{ Hábito } & \multicolumn{4}{|c|}{ Categorías de riesgo } & \multirow{2}{*}{ Endemismo } \\
\hline & & & NOM-059 & CITES & LR-UICN & LR-BMM & \\
\hline
\end{tabular}

Paspalum conjugatum P.J. Bergius

LC

Paspalum squamulatum E. Fourn.

LC

Schizachyrium brevifolium (Sw.) Nees ex Buse

$\mathrm{H}$

Tripsacum pilosum Scribn. \& Merr.

LC

Tristachya contrerasii R. Guzmán

LC

\section{Eudicotiledóneas}

Acanthaceae

Dyschoriste angustifolia (Hemsl.) Kuntze

$\mathrm{H}$

Actinidiaceae

Saurauia serrata DC.

Amaranthaceae

Anacardiaceae

Apiaceae

Apocynaceae

Pleuropetalum sprucei (Hook. f.) Standl.

Rhus terebinthifolia Schltdl. \& Cham.

Eryngium jaliscense Mathias \& Constance

Asclepias mcvaughii Woodson

Cascabela ovata (Cav.) Lippold

Tabernaemontana donnell-smithii Rose

Tabernaemontana grandiflora Jacq.

Tabernaemontana tomentosa (Greenm.) A.O.

Simões \& M.E. Endress

Vallesia spectabilis El. Mey. ex J.F. Morales

Aquifoliaceae

Ilex brandegeana Loes.

Ilex dugesii Fernald

$\mathrm{Ar}$

$\mathrm{Ar}$

$\mathrm{H}$

$\mathrm{H}$

$\mathrm{H}$

A

A

A

$\mathrm{JAL}$

Araliaceae

Dendropanax arboreus (L.) Decne. \& Planch.

Oreopanax peltatus Linden ex Regel

Oreopanax xalapensis (Kunth) Decne. \& Planch.

Asteraceae

Acourtia hooveri (McVaugh) Reveal \& R.M. King

$\operatorname{Pr}$

EN

LC

COL, JAL, $\mathrm{MICH}$

VU

LC

COL, JAL

Pr

LC

LC

LC

LC

Pr

CR

$J A L$

LC

LC

VU

LC

VU

NT

NT

COL, JAL, $\mathrm{MICH}$

*JAL

COL, JAL,

$\mathrm{MICH}, \mathrm{NAY}$ 
Hábito

NOM-059

Categorías de riesgo

CITES

\section{LR-UICN}

LR-BMM

Ageratina halbertiana (McVaugh) R.M. King \&

H. Rob.

Ageratina jaliscensis (B.L. Rob.) Gage ex B.L.

Turner

Ageratina leptodictyon (A. Gray) R.M. King \& H. Rob.

Ageratina mairetiana (DC.) R.M. King \& H. Rob. Ageratina triniona (McVaugh) R.M. King \& H. Rob.

Brickellia adenolepis (B.L. Rob.) Shinners

Brickellia jaliscensis McVaugh

Critoniopsis baadii (McVaugh) H. Rob.

Critoniopsis macphersonii (S.B. Jones \& Stutts)

H. Rob.

Hofmeisteria mexiae (B.L. Rob.) B.L. Turner

Lasianthaea fruticosa var. fasciculata (DC.) K.M.

Becker

Lepidaploa koelzii (McVaugh) H. Rob.

Montanoa leucantha subsp. arborescens (DC.)

V.A. Funk

Pluchea carolinensis (Jacq.) G. Don

Podachaenium eminens (Lag.) Sch. Bip.

Psacalium eriocarpum (S.F. Blake) S.F. Blake

Roldana guadalajarensis (B.L. Rob.) H. Rob. \& Brettell

Sinclairia glabra var. hypoleuca (Greenm.) B.L. Turner

Stevia reticulata Grashoff

$\mathrm{H}$

Stevia urceolata Grashoff

Ar

Ar

A

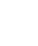

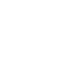

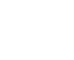

Ar

COL, JAL,
MICH
COL, JAL,
NAY
COL, DGO,
JAL, NAY, ZAC




\begin{tabular}{|c|c|c|c|c|c|c|c|}
\hline \multirow{2}{*}{ Grupo/Familia } & \multirow{2}{*}{ Taxones } & \multirow{2}{*}{ Hábito } & \multicolumn{4}{|c|}{ Categorías de riesgo } & \multirow{2}{*}{ Endemismo } \\
\hline & & & NOM-059 & CITES & LR-UICN & LR-BMM & \\
\hline & Trixis inula Crantz & $\operatorname{Ar}$ & & & LC & & \\
\hline & Verbesina glaucophylla S.F. Blake & $\operatorname{Ar}$ & & & & & JAL \\
\hline & & & & & & & AGS, COL, \\
\hline & Vernonia bealliae McVaugh & $\operatorname{Ar}$ & & & & & $\mathrm{JAL}, \mathrm{MICH}$ \\
\hline & & & & & & & ZAC \\
\hline \multirow[t]{4}{*}{ Betulaceae } & Alnus acuminata subsp. arguta (Schltdl.) Furlow & A & & & LC & LC & \\
\hline & Alnus jorullensis Kunth & A & & & LC & LC & \\
\hline & Carpinus tropicalis (Donn. Sm.) Lundell & A & $A$ & & LC & NT & \\
\hline & Ostrya virginiana (Mill.) K. Koch & A & $\operatorname{Pr}$ & & LC & NT & \\
\hline \multirow[t]{3}{*}{ Bignoniaceae } & Godmania aesculifolia (Kunth) Standl. & A & & & LC & & \\
\hline & Tabebuia rosea (Bertol.) DC. & A & & & LC & & \\
\hline & Tecoma stans (L.) Juss. ex Kunth & $\operatorname{Ar}$ & & & LC & & \\
\hline \multirow[t]{2}{*}{ Bixaceae } & Bixa orellana $\mathrm{L}$. & $\operatorname{Ar}$ & & & LC & & \\
\hline & Cochlospermum vitifolium (Willd.) Spreng. & A & & & LC & & \\
\hline Boraginaceae & Wigandia urens (Ruiz \& Pav.) Kunth & $\mathrm{Ar}$ & & & LC & & \\
\hline Brassicaceae & Chaunanthus acuminatus (Rollins) R.A. Price \& & $\mathrm{H}$ & & & & & COL, JAL \\
\hline & Al-Shehbaz & & & & & & \\
\hline \multirow[t]{3}{*}{ Burseraceae } & Bursera bipinnata (DC.) Engl. & A & & & LC & & \\
\hline & Bursera penicillata (DC.) Engl. & A & & & LC & & \\
\hline & Bursera vazquezyanesii Rzed. \& Calderón & A & & & EN & & JAL \\
\hline \multirow[t]{8}{*}{ Cactaceae } & Epiphyllum anguliger (Lem.) H.P. Kelsey \& & $\mathrm{Ar}$ & & II & LC & & \\
\hline & Dayton & & & & & & \\
\hline & Opuntia bensonii Sánchez-Mej. & $\mathrm{Ar}$ & & II & & & \\
\hline & Opuntia jaliscana Bravo & $\operatorname{Ar}$ & & II & & & \\
\hline & Opuntia karwinskiana Salm-Dyck & $\operatorname{Ar}$ & & II & & & \\
\hline & Peniocereus serpentinus (Lag. \& Rodr.) N.P. & $\mathrm{H}$ & & II & LC & & \\
\hline & Taylor & & & & & & \\
\hline & Selenicereus atropilosus Kimnach & $\mathrm{T}$ & $\operatorname{Pr}$ & II & EN & & COL, JAL \\
\hline \multirow[t]{2}{*}{ Calophyllaceae } & Calophyllum brasiliense var. rekoi (Standl.) & A & A & & LC & & \\
\hline & Standl. & & & & & & \\
\hline
\end{tabular}




\begin{tabular}{|c|c|c|c|c|c|c|c|}
\hline \multirow{2}{*}{ Grupo/Familia } & \multirow{2}{*}{ Taxones } & \multirow{2}{*}{ Hábito } & \multicolumn{4}{|c|}{ Categorías de riesgo } & \multirow{2}{*}{ Endemismo } \\
\hline & & & NOM-059 & CITES & LR-UICN & LR-BMM & \\
\hline Campanulaceae & Lobelia jaliscensis McVaugh & $\mathrm{H}$ & & & & & $\begin{array}{l}\mathrm{COL}, \mathrm{JAL} \\
\mathrm{MICH}, \mathrm{NAY}, \\
\mathrm{ZAC}\end{array}$ \\
\hline Cannabaceae & Trema micrantha (L.) Blume & $A$ & & & & LC & \\
\hline \multirow[t]{2}{*}{ Capparaceae } & $\begin{array}{l}\text { Capparidastrum mollicellum (Standl.) Cornejo } \\
\text { \& Iltis }\end{array}$ & A & & & LC & & \\
\hline & Quadrella indica (L.) Iltis \& Cornejo & $A$ & & & LC & & \\
\hline Celastraceae & Zinowiewia concinna Lundell & $A$ & $\mathrm{P}$ & & & EN & \\
\hline \multirow[t]{3}{*}{ Clethraceae } & Clethra fragrans L.M. González \& R. Delgad. & $A$ & & & EN & LC & COL, JAL \\
\hline & Clethra hartwegii Britton & $A$ & & & LC & LC & \\
\hline & Clethra rosei Britton & A & & & LC & LC & \\
\hline \multirow[t]{2}{*}{ Clusiaceae } & Clusia salvinii Donn. Sm. & $A$ & & & LC & LC & \\
\hline & Garcinia intermedia (Pittier) Hammel & A & & & LC & LC & \\
\hline Convolvulaceae & Ipomoea spectata J.A. McDonald & $\mathrm{T}$ & & & & LC & $\begin{array}{l}\text { COL, JAL, } \\
\text { MICH }\end{array}$ \\
\hline \multirow[t]{2}{*}{ Cornaceae } & Cornus disciflora DC. & $A$ & & & VU & VU & \\
\hline & Cornus excelsa Kunth & A & & & LC & LC & \\
\hline \multirow[t]{2}{*}{ Crassulaceae } & Sedum grandipetalum Fröd. & $\mathrm{H}$ & & & & & $\mathrm{JAL}$ \\
\hline & Villadia platystyla (Fröd.) R.T. Clausen & $\mathrm{H}$ & & & & & $J A L$ \\
\hline Dipentodontaceae & Perrottetia longistylis Rose & A & & & LC & LC & \\
\hline \multirow[t]{4}{*}{ Ericaceae } & Arbutus xalapensis Kunth & A & & & $\mathrm{LR} / \mathrm{LC}$ & LC & \\
\hline & Bejaria aestuans Mutis ex L. & $\mathrm{Ar}$ & & & LC & LC & \\
\hline & $\begin{array}{l}\text { Comarostaphylis discolor (Hook.) Diggs subsp. } \\
\text { discolor }\end{array}$ & A & $\operatorname{Pr}$ & & $\mathrm{LR} / \mathrm{LC}$ & LC & \\
\hline & Vaccinium stenophyllum Steud. & $\mathrm{Ar}, \mathrm{A}$ & & & & EN & \\
\hline \multirow[t]{5}{*}{ Euphorbiaceae } & Alchornea latifolia Sw. & A & & & LC & LC & \\
\hline & Croton draco Schltdl. \& Cham. & A & & & LC & LC & \\
\hline & Croton suberosus Kunth & $\operatorname{Ar}$ & & & LC & & \\
\hline & Croton ynesiae Croizat & Ar & & & VU & & $\begin{array}{l}\text { COL, JAL, } \\
\text { NAY }\end{array}$ \\
\hline & Gymnanthes actinostemoides Müll. Arg. & $A$ & & & & LC & \\
\hline \multirow[t]{2}{*}{ Fabaceae } & $\begin{array}{l}\text { Acaciella angustissima (Mill.) Britton \& Rose } \\
\text { var. angustissima }\end{array}$ & A & & & LC & & \\
\hline & Andira inermis (W. Wright) Kunth ex DC. & $A$ & & & LC & & \\
\hline
\end{tabular}


Hábito

NOM-059

\section{Categorías de riesgo} CITES

LR-UICN
Astragalus jaliscensis (Rydb.) Barneby

Brongniartia mortonii McVaugh

Calliandra houstoniana (Mill.) Standl.

Calliandra sesquipedalis McVaugh

Canavalia hirsutissima J.D. Sauer

Chamaecrista viscosa (Kunth) H.S. Irwin \& Barneby var. viscosa

Coursetia glandulosa A. Gray

Crotalaria cajanifolia Kunth

Crotalaria longirostrata Hook. \& Arn.

Crotalaria micans Link

Crotalaria rotundifolia var. vulgaris Windler

Dalea abietifolia (Rose ex Rydb.) Bullock

Dalea leucostachya var. eysenhardtioides (Hemsl.) Barneby

Desmodium angustatum (Rose \& Standl.)

Standl.

Desmodium occidentale (Morton) Standl.

Desmodium saxatile (Morton) B.G. Schub. \&

McVaugh

Desmodium skinneri var. flavovirens B.G. Schub. \& McVaugh

Eysenhardtia polystachya (Ortega) Sarg

Hymenaea courbaril L.

Inga andersonii McVaugh

Inga hintonii Sandwith

Inga laurina (Sw.) Willd.

Lonchocarpus guatemalensis Benth.

Lupinus rotundiflorus M.E. Jones

Machaerium kegelii Meisn. $\mathrm{H}$ LR-BMM

Endemismo AGS, JAL,

LC

LC

JAL

LC

LC

LC

LC

LC

LC

LC

JAL, MICH, NAY, ZAC

VU

JAL, NAY, ZAC

COL, JAL

*JAL

JAL

LC

LC

VU

JAL, NAY

EN

LC

LC

LC

JAL, NAY 


\begin{tabular}{|c|c|c|c|c|c|c|c|}
\hline \multirow[t]{2}{*}{ Grupo/Familia } & \multirow[t]{2}{*}{ Taxones } & \multirow[t]{2}{*}{ Hábito } & \multicolumn{4}{|c|}{ Categorías de riesgo } & \multirow[t]{2}{*}{ Endemismo } \\
\hline & & & NOM-059 & CITES & LR-UICN & LR-BMM & \\
\hline & $\begin{array}{l}\text { Mimosa albida Humb. \& Bonpl. ex Willd. var. } \\
\text { albida }\end{array}$ & $\mathrm{T}$ & & & LC & & \\
\hline & $\begin{array}{l}\text { Mimosa albida Humb. \& Bonpl. ex Willd. var. } \\
\text { strigosa B.L. Rob. }\end{array}$ & $\mathrm{T}$ & & & LC & & \\
\hline & Phaseolus coccineus L. & $\mathrm{T}$ & & & LC & & \\
\hline & Phaseolus jaliscanus Piper & $\mathrm{T}$ & & & LC & & \\
\hline & Phaseolus lunatus L. & $\mathrm{T}$ & & & LC & & \\
\hline & Phaseolus micranthus Hook. \& Arn. & $\mathrm{T}$ & & & LC & & \\
\hline & Phaseolus pauciflorus Sessé \& Moc. Ex G. Don & $\mathrm{T}$ & & & LC & & \\
\hline & Phaseolus perplexus A. Delgado & $\mathrm{T}$ & & & LC & & \\
\hline & Phaseolus vulgaris L. & $\mathrm{T}$ & & & LC & & \\
\hline & Senna foetidissima (Sessé \& Moc. ex G. Don) & $\operatorname{Ar}$ & & & LC & & \\
\hline & H.S. Irwin \& Barneby var. foetidissima & & & & & & \\
\hline & $\begin{array}{l}\text { Senna foetidissima var. grandiflora (Benth.) H.S. } \\
\text { Irwin \& Barneby }\end{array}$ & $\operatorname{Ar}$ & & & LC & & \\
\hline & Senna fruticosa (Mill.) H.S. Irwin \& Barneby & $\operatorname{Ar}$ & & & LC & & \\
\hline & $\begin{array}{l}\text { Senna nicaraguensis (Benth.) H.S. Irwin \& } \\
\text { Barneby }\end{array}$ & $\operatorname{Ar}$ & & & LC & & \\
\hline & $\begin{array}{l}\text { Senna quinquangulata (Rich.) H.S. Irwin \& Bar- } \\
\text { neby var. quinquangulata }\end{array}$ & $\mathrm{T}$ & & & LC & & \\
\hline & Senna talpana H.S. Irwin \& Barneby & $\operatorname{Ar}$ & & & & & COL, JAL \\
\hline & Tephrosia diversifolia (Rose) J.F. Macbr. & H & & & & & JAL, MICH \\
\hline & Tephrosia platyphylla (Rose) Standl. & $\mathrm{H}$ & & & & & JAL \\
\hline & Trifolium amabile Kunth & $\mathrm{H}$ & & & LC & & \\
\hline & $\begin{array}{l}\text { Zapoteca portoricensis (Jacq.) H.M. Hern. } \\
\text { subsp. portoricensis }\end{array}$ & $\operatorname{Ar}$ & & & & LC & \\
\hline \multirow[t]{4}{*}{ Fagaceae } & Quercus acutifolia Née & $A$ & & & VU & & \\
\hline & Quercus aristata Hook. \& Arn. & A & & & LC & & \\
\hline & Quercus calophylla Schltdl. \& Cham. & $A$ & & & LC & & \\
\hline & Quercus castanea Née & $A$ & & & LC & & \\
\hline
\end{tabular}


Apéndice. Continuación

\begin{tabular}{|c|c|c|c|c|c|c|c|}
\hline \multirow[t]{2}{*}{ Grupo/Familia } & \multirow[t]{2}{*}{ Taxones } & \multirow[t]{2}{*}{ Hábito } & \multicolumn{4}{|c|}{ Categorías de riesgo } & \multirow[t]{2}{*}{ Endemismo } \\
\hline & & & NOM-059 & CITES & LR-UICN & LR-BMM & \\
\hline & Quercus centenaria L.M. González & $A$ & & & & & $\begin{array}{l}\text { COL, JAL, } \\
\text { NAY }\end{array}$ \\
\hline & Quercus crassifolia Bonpl. & $A$ & & & LC & LC & \\
\hline & Quercus eduardii Trel. & $A$ & & & LC & & \\
\hline & Quercus elliptica Née & $A$ & & & LC & VU & \\
\hline & Quercus gentryi C.H. Mull. & A & & & LC & & \\
\hline & Quercus glaucoides M. Martens \& Galeotti & A & & & LC & & \\
\hline & Quercus iltisii L.M. González & A & & & & & COL, JAL \\
\hline & Quercus laeta Liebm. & A & & & LC & & \\
\hline & Quercus magnoliifolia Née & A & & & LC & & \\
\hline & Quercus martinezii C.H. Mull. & A & & & LC & $\mathrm{CR}$ & \\
\hline & Quercus mexiae L.M. González & A & & & & & $J A L$ \\
\hline & Quercus obtusata Bonpl. & A & & & LC & LC & \\
\hline & Quercus peduncularis Née & A & & & LC & & \\
\hline & Quercus planipocula Trel. & $A$ & & & LC & & \\
\hline & Quercus resinosa Liebm. & A & & & LC & & \\
\hline & Quercus rugosa Née & A & & & LC & LC & \\
\hline & Quercus scytophylla Liebm. & A & & & LC & LC & \\
\hline & Quercus viminea Trel. & A & & & LC & & \\
\hline Garryaceae & Garrya laurifolia Hartw. ex Benth. & A & & & & VU & \\
\hline Geraniaceae & Geranium latilobum H.E. Moore & $\mathrm{H}$ & & & & & $J A L$ \\
\hline Hamamelidaceae & Matudaea trinervia Lundell & A & A & & VU & VU & \\
\hline \multirow[t]{2}{*}{ Juglandaceae } & Juglans major var. glabrata W.E. Manning & A & A & & LC & & \\
\hline & Juglans mollis Engelm. & A & & & & NT & \\
\hline \multirow[t]{7}{*}{ Lamiaceae } & Cunila jaliscana García-Peña \& J.G. González & $\operatorname{Ar}$ & & & & & $J A L$ \\
\hline & Hedeoma bella (Epling) R.S. Irving & $\mathrm{H}$ & & & & & $J A L$ \\
\hline & Hyptis pinetorum Epling & $\mathrm{Ar}$ & & & & & $J A L$ \\
\hline & Salvia angustiarum Epling & HS & & & & & JAL, NAY, ZAC \\
\hline & Salvia ibugana J.G. González & $\mathrm{Ar}$ & & & & & $J A L$ \\
\hline & Salvia firma Fernald & $\mathrm{H}$ & & & & & JAL, NAY \\
\hline & Salvia mexiae Epling & $\mathrm{H}$ & & & & & JAL \\
\hline
\end{tabular}




\begin{tabular}{|c|c|c|c|c|c|c|c|}
\hline \multirow[t]{2}{*}{ Grupo/Familia } & \multirow[t]{2}{*}{ Taxones } & \multirow[t]{2}{*}{ Hábito } & \multicolumn{4}{|c|}{ Categorías de riesgo } & \multirow[t]{2}{*}{ Endemismo } \\
\hline & & & NOM-059 & CITES & LR-UICN & LR-BMM & \\
\hline & Salvia platyphylla Briq. & $\mathrm{H}$ & & & & & JAL, NAY, ZAC \\
\hline & Salvia quercetorum Epling & Ar & & & & & JAL \\
\hline & Salvia ramirezii J.G. González & $\mathrm{H}$ & & & & & $J A L$ \\
\hline & Vitex hemsleyi Briq. & $A$ & & & LC & & \\
\hline Loranthaceae & Cladocolea cupulata Kuijt & $P$ & & & & & DGO, JAL \\
\hline Lythraceae & Cuphea mexiae Bacig. & Ar & & & & & $* J A L$ \\
\hline \multirow[t]{4}{*}{ Malpighiaceae } & Bunchosia luzmariae W.R. Anderson & Ar, A & & & & & JAL, NAY \\
\hline & Byrsonima crassifolia (L.) Kunth & A & & & LC & & \\
\hline & Heteropterys laurifolia (L.) A. Juss. & $\mathrm{T}$ & & & LC & & \\
\hline & Malpighia wilburiorum W.R. Anderson & A & & & & & COL, JAL \\
\hline \multirow[t]{11}{*}{ Malvaceae } & Abutilon jaliscanum Standl. & Ar & & & & & *JAL \\
\hline & Bernoullia flammea Oliv. & A & & & LC & & \\
\hline & Malvaviscus arboreus Cav. var. mexicanus & $\operatorname{Ar}$ & & & LC & LC & \\
\hline & Schltdl. & & & & & & \\
\hline & Periptera macrostelis Rose & Ar & $\operatorname{Pr}$ & & & & \\
\hline & Tilia americana var. mexicana (Schltdl.) Hardin & A & $P$ & & LC & VU & \\
\hline & Triumfetta barbosa Lay & $\operatorname{Ar}$ & & & & & COL, JAL \\
\hline & Triumfetta cucullata Fernald & $\operatorname{Ar}$ & & & & & DGO, JAL, \\
\hline & & & & & & & NAY \\
\hline & Triumfetta indurata W.W. Thomas \& McVaugh & $\operatorname{Ar}$ & & & & & $J A L$ \\
\hline & Triumfetta semitriloba Jacq. & $\operatorname{Ar}$ & & & LC & & \\
\hline \multirow[t]{5}{*}{ Melastomataceae } & Conostegia volcanalis Standl. \& Steyerm. & A & & & & VU & \\
\hline & Conostegia xalapensis (Bonpl.) D. Don ex DC. & $\operatorname{Ar}$ & & & LC & LC & \\
\hline & Miconia glaberrima (Schltdl.) Naudin & $\operatorname{Ar}$ & & & LC & LC & \\
\hline & Miconia mexicana (Bonpl.) Naudin & $\operatorname{Ar}$ & & & & VU & \\
\hline & Tibouchina longifolia (Vahl) Baill. & $\operatorname{Ar}$ & & & LC & & \\
\hline \multirow[t]{4}{*}{ Meliaceae } & Cedrela odorata L. & A & $\operatorname{Pr}$ & II & VU & & \\
\hline & Guarea glabra Vahl & A & & & LC & NT & \\
\hline & Trichilia americana (Sessé \& Moc.) T.D. Penn. & A & & & LC & & \\
\hline & Trichilia havanensis Jacq. & A & & & LC & LC & \\
\hline \multirow[t]{2}{*}{ Moraceae } & Ficus aurea Nutt. & A & & & & LC & \\
\hline & Ficus citrifolia Mill. & $A$ & & & LC & & \\
\hline
\end{tabular}




\begin{tabular}{|c|c|c|c|c|c|c|c|}
\hline \multirow[t]{2}{*}{ Grupo/Familia } & \multirow[t]{2}{*}{ Taxones } & \multirow[t]{2}{*}{ Hábito } & \multicolumn{4}{|c|}{ Categorías de riesgo } & \multirow[t]{2}{*}{ Endemismo } \\
\hline & & & NOM-059 & CITES & LR-UICN & LR-BMM & \\
\hline & Ficus maxima Mill. & A & & & LC & & \\
\hline & Ficus obtusifolia Kunth & $A$ & & & LC & & \\
\hline & Ficus velutina Humb. \& Bonpl. ex Willd. & $A$ & & & & LC & \\
\hline & Trophis mexicana (Liebm.) Bureau & $A$ & & & LC & LC & \\
\hline & Trophis racemose subsp. ramon (Schltdl. \& & $A$ & & & LC & LC & \\
\hline & Cham.) W.C. Burger & & & & & & \\
\hline Myricaceae & Morella cerifera (L.) Small. & A & & & & LC & \\
\hline \multirow[t]{6}{*}{ Myrtaceae } & Calyptranthes schiedeana O. Berg. & $A$ & & & & EN & \\
\hline & Eugenia capuli (Schltdl. \& Cham.) Hook. \& Arn. & A & & & LC & LC & \\
\hline & Eugenia culminicola McVaugh & $\operatorname{Ar}$ & & & & EN & \\
\hline & Eugenia harkerae E. Sánchez-Chávez \& Zamudio & $\operatorname{Ar}$ & & & & & *JAL \\
\hline & Myrcianthes fragrans (Sw.) McVaugh & $A$ & & & LC & LC & \\
\hline & Psidium guineense Sw. & $\operatorname{Ar}$ & & & LC & & \\
\hline Oleaceae & Fraxinus uhdei (Wenz.) Lingelsh. & $A$ & & & LC & LC & \\
\hline \multirow[t]{2}{*}{ Onagraceae } & Diplandra lopezioides Hook. \& Arn. & $\operatorname{Ar}$ & & & & & JAL, NAY \\
\hline & Fuchsia arborescens Sims & $A$ & & & & LC & \\
\hline Papaveraceae & Bocconia arborea S. Watson & A & & & LC & LC & \\
\hline \multirow[t]{2}{*}{ Pentaphylacaceae } & Symplococarpon purpusii (Brandegee) Kobuski & A & & & & VU & \\
\hline & Ternstroemia lineata DC. & $A$ & & & LC & NT & \\
\hline Phrymaceae & Mimulus floribundus Lindl. & $\mathrm{H}$ & & & LC & & \\
\hline Picramniaceae & Picramnia guerrerensis W.W. Thomas & A & & & & EN & \\
\hline Polygalaceae & Monnina xalapensis Kunth & $\mathrm{Ar}$ & & & LC & & \\
\hline Polygonaceae & Coccoloba floribunda (Benth.) Lindau & $A$ & & & LC & & \\
\hline \multirow[t]{3}{*}{ Primulaceae } & Ardisia compressa Kunth & $A$ & & & LC & LC & \\
\hline & Ardisia revoluta Kunth & $A$ & & & & NT & \\
\hline & $\begin{array}{l}\text { Bonellia macrocarpa (Cav.) B. Ståhl \& Källersjö } \\
\text { subsp. macrocarpa }\end{array}$ & $A$ & & & LC & & \\
\hline
\end{tabular}




\begin{tabular}{|c|c|c|c|c|c|c|c|}
\hline \multirow{2}{*}{ Grupo/Familia/ } & \multirow{2}{*}{ Taxones } & \multirow{2}{*}{ Hábito } & \multicolumn{4}{|c|}{ Categorías de riesgo } & \multirow{2}{*}{ Endemismo } \\
\hline & & & NOM-059 & CITES & LR-UICN & LR-BMM & \\
\hline & Myrsine coriacea (Sw.) R. Br. ex Roem. \& Schult. & A & & & & LC & \\
\hline & Myrsine juergensenii (Mez) Ricketson \& Pipoly & $A$ & & & & NT & \\
\hline & Parathesis melanosticta (Schltdl.) Hemsl. & $A$ & & & & VU & \\
\hline & Parathesis villosa Lundell & A & & & & EN & \\
\hline Rhamnaceae & Colubrina triflora Brongn. ex G. Don & Ar, A & & & LC & & \\
\hline \multirow[t]{7}{*}{ Rosaceae } & Crataegus mexicana DC. & $A$ & & & LC & LC & \\
\hline & Photinia mexicana (Baill.) Hemsl. & $A$ & & & & VU & \\
\hline & $\begin{array}{l}\text { Photinia microcarpa Standl. subsp. hintonii J.B. } \\
\text { Phipps }\end{array}$ & $A$ & & & & VU & \\
\hline & Photinia oblongifolia Standl. & $A$ & & & & & $\begin{array}{l}\text { JAL, MICH, } \\
\text { NAY }\end{array}$ \\
\hline & Prunus cortapico Kerber ex Koehne & A & & & & VU & \\
\hline & Prunus serotina subsp. capuli (Cav.) McVaugh & $A$ & & & LC & LC & \\
\hline & Prunus tetradenia Koehne & $A$ & & & & VU & \\
\hline \multirow[t]{10}{*}{ Rubiaceae } & Bouvardia loeseneriana Standl. & Ar & $\operatorname{Pr}$ & & & & \\
\hline & Chiococca alba (L.) Hitchc. & Ar, A & & & LC & & \\
\hline & Faramea occidentalis (L.) A. Rich. & Ar, A & & & & LC & \\
\hline & Glossostipula concinna (Standl.) Lorence & $A$ & & & & EN & \\
\hline & Hamelia patens Jacq. & Ar, A & & & $\mathrm{LC}$ & LC & \\
\hline & Psychotria trichotoma M. Martens \& Galeotti & $A$ & & & LC & LC & \\
\hline & Randia aculeata $\mathrm{L}$. & Ar, A & & & LC & & \\
\hline & Randia armata (Sw.) DC. & Ar, A & & & LC & & \\
\hline & Rogiera amoena Planch. & Ar, A & & & & VU & \\
\hline & Sommera grandis (Bartl. Ex DC.) Standl. & Ar, A & & & & VU & \\
\hline \multirow[t]{3}{*}{ Rutaceae } & Amyris mexicana Lundell & $A$ & & & & & $\begin{array}{l}\text { COL, JAL, } \\
\text { MICH }\end{array}$ \\
\hline & Amyris rekoi S.F. Blake & $A$ & & & & VU & \\
\hline & Zanthoxylum mollissimum (Engl.) P. Wilson & A & & & $\mathrm{LC}$ & LC & \\
\hline \multirow[t]{2}{*}{ Sabiaceae } & Meliosma dentata (Liebm.) Urb. & A & & & & NT & \\
\hline & Meliosma nesites I.M. Johnst. & $A$ & & & & EN & COL, JAL \\
\hline \multirow[t]{2}{*}{ Salicaceae } & Casearia arguta Kunth & A & & & LC & NT & \\
\hline & Casearia sylvestris Sw. & $A$ & & & LC & LC & \\
\hline
\end{tabular}


Populus guzmanantlensis A.Vázquez \& Cuevas

Salix taxifolia Kunth

Xylosma flexuosa (Kunth) Hemsl.

Xylosma panamensis Turcz.

Sapindaceae

Sapotaceae

Simaroubaceae

Solanaceae

Staphyleaceae

Styracaceae

Symplocaceae

Thymelaeaceae

Urticaceae

Cupania dentata DC.

Cupania glabra Sw.

Sideroxylon capiri subsp. tempisque (Pittier) T.D.

Penn.

Sideroxylon cartilagineum (Cronquist) T.D.

Penn.

Buddleja americana $\mathrm{L}$.

Buddleja parviflora Kunth

Picrasma mexicana Brendegee

Brachistus stramoniifolius (Kunth) Miers

Cestrum tomentosum L. $\mathrm{f}$.

Physalis philadelphica Lam.

Physalis pruinosa $\mathrm{L}$.

Solanum aphyodendron S. Knapp

Solanum hazenii Britton

Solanum nigricans M. Martens \& Galeotti

Solanum verrucosum Schltdl.

Turpinia occidentalis (Sw.) G. Don subsp. occidentalis

Styrax radians P.W. Fritsch

Styrax ramirezii Greenm.

Symplocos novogaliciana L.M. González

Daphnopsis americana (Mill.) J.R. Johnst.

Daphnopsis mexiae Nevling

Boehmeria ulmifolia Wedd.
A

A

A

A

A

A

Ar

Ar, A

A

$\mathrm{H}$

Ar

$\mathrm{H}$

$\mathrm{H}$

$\mathrm{Ar}$

A

Ar

$\mathrm{H}$

A

A

A

A

Ar

Ar

Ar

A

Cecropia obtusifolia Bertol.

$\operatorname{Pr}$

$\begin{array}{ll}\text { EN } & \text { VU } \\ \text { LC } & \text { LC } \\ \text { LC } & \text { LC } \\ \text { LC } & \\ & \text { LC } \\ \text { LC } & \text { LC }\end{array}$

LR/NT

$\mathrm{COL}, \mathrm{JAL}$

LC

LC

LC

LR/NT

LC

LC

LC

P

LC

LC

LC

LC

LC

LC

LC

LC

LC

LC

LC

NT

NT

LC

EN COL, JAL,

LC

JAL, NAY 
Apéndice. Continuación.

Grupo/Familia

Taxones

Hábito

Categorías de riesgo
LR-UICN
CITES
VU

Coussapoa purpusii Standl.

Myriocarpa longipes Liebm.

Urera baccifera (L.) Gaudich. ex Wedd.

Urera caracasana (Jacq.) Gaudich. ex Griseb.

Verbenaceae

Lippia umbellata Cav.

Guaiacum coulteri A. Gray

\section{A}

Ar

Ar

A
Zygophyllaceae
LC

LC

A
NOM-059 